\title{
Spatiotemporal modelling for integrated spatial and energy planning
}

\author{
Luis Ramirez Camargo ${ }^{1}$ and Gernot Stoeglehner ${ }^{2^{*}}$ (D)
}

\begin{abstract}
The transformation of the energy system to a renewable one is crucial to enable sustainable development for mankind. The integration of high shares of renewable energy sources (RES) in the energy matrix is, however, a major challenge due to the low energy density per area unit and the stochastic temporal patterns in which RES are available. Distributed generation for energy supply becomes necessary to overcome this challenge, but it sets new pressures on the use of space. To optimize the use of space, spatial planning and energy planning have to be integrated, and suitable tools to support this integrated planning process are fundamental.

Spatiotemporal modelling of RES is an emerging research field that aims at supporting and improving the planning process of energy systems with high shares of RES. This paper contributes to this field by reviewing latest developments and proposing models and tools for planning distributed energy systems for municipalities. The models provide estimations of the potentials of fluctuating RES technologies and energy demand in high spatiotemporal resolutions, and the planning tools serve to configure energy systems of multiple technologies that are customized for the local energy demand. Case studies that test the spatiotemporal models and their transferability were evaluated to determine the advantages of using these instead of merely spatial models for planning municipality-wide RES-based energy systems.

Spatiotemporal models allow a more detailed estimation of RES potentials and serve to find not only optimal locations but also optimal sizes for individual RES plants. While the potential of variable RES based on yearly energy generation values can be considerably larger than the energy demand, only a fraction of it can be deployed without compromising the quality and reliability of the local energy supply system. Furthermore, when spatiotemporal models are used, it can be seen that technological diversity is beneficial for the supply quality. Similarly, the advantages and limits of the deployment of storage systems and of combinations of RES-based technologies to cover the local demand were determined and evaluated. Finally, the results from the analyses provide sufficient information to define road maps of installations deployment to achieve desired RES penetration objectives.
\end{abstract}

Keywords: Spatiotemporal modelling, Integrated spatial and energy planning, Renewable energies, Open source GIS, Virtual power plants

\section{Background}

The transformation of the energy system has become a global affair that is already generating important economical, societal and technical changes. Countries worldwide are setting ambitious goals to replace their fossil-based energy matrix by a renewable one. Several of the renewable energy sources (RES) promotion and

\footnotetext{
* Correspondence: gernot.stoeglehner@boku.ac.at

${ }^{2}$ Institute of Spatial Planning, Environmental Planning and Land Rearrangement, University of Natural Resources and Life Sciences Vienna, Peter-Jordan-Strasse 82, 1190 Vienna, Austria

Full list of author information is available at the end of the article
}

adoption initiatives of these countries present significant and continuous progress. However, the medium- and long-term objectives of high levels of RES [1] can only be achieved if there is a transformation from the current centralized energy generation paradigm towards distributed generation [2-4]. Such a structural transformation has started to take place in countries such as Germany where the actual installed RES capacity is distributed in around 1.5 million installations [5]. This figure contrasts with the 730 operational conventional power plants with nominal capacities above $10 \mathrm{MW}$ that are responsible

(c) The Author(s). 2018 Open Access This article is distributed under the terms of the Creative Commons Attribution 4.0 International License (http://creativecommons.org/licenses/by/4.0/), which permits unrestricted use, distribution, and reproduction in any medium, provided you give appropriate credit to the original author(s) and the source, provide a link to the Creative Commons license, and indicate if changes were made. 
for supplying the largest part of the country's electricity demand [6].

Consequently, the decentralization of the energy system sets new pressures on the use of space and on administrative units such as districts and municipalities. Space becomes a precious object not only for food provision, for environmental services and for residential, commercial, industrial and transport uses but also for the energy supply infrastructure [7]. Moreover, the decisions about infrastructure no longer concern isolated installations that are as distant as possible to human settlements, but new infrastructure is to be installed directly in buildings and close to populated areas. The decentralization of the energy system therefore entails a radical transformation of cityscapes and landscapes [8]. In order to overcome the issues with space usage and to accomplish acceptance and understanding from society to implement the necessary changes, relatively small administrative units such as districts and municipalities have to take an active role in the design of the new energy system [9, 10]. Furthermore, since the technical solution cannot be separated from economic, environmental, social, political and spatial concerns [11], the conception of a decentralized RES-based energy system requires the coupling of spatial and energy planning [8].

Geographic information systems (GIS) have shown to be valuable tools to support both energy and spatial planning, but these must be further developed in order to assist the conception of a RES-based energy system. GIS have become indispensable to assess RES potentials and local impacts [12], as well as to evaluate RES adoption by considering technical, environmental, social, economic and political criteria [13]. GIS-based studies and tools for the assessment of solar, wind, biomass, wave and geothermal energy potentials in a multitude of locations around the world populate RES-related scientific literature of the last decade [12-14]. However, the consideration of the local energy demand, the constraints given by the grid and the spatially explicit examination of the temporal variability of RES, such as wind and solar energy, are only starting to appear in the current research agenda dealing with the conception of energy systems for municipalities. These aspects are vital if the intention is to conceive energy systems that ensure reliable supply and economic feasibility.

The integration of high shares of technologies such as photovoltaics and wind turbines in the energy matrix is a challenge. Inappropriate planning for the integration of such technologies would lead to lower revenues, degradation of the quality of supply, and increased infrastructure requirements related to the grid, storage, and back-up systems [15-18]. The design of energy supply systems such as virtual power plants (understood in Europe as a system resulting from the aggregation of
RES-based energy generation plants to supply a desired demand in a reliable manner [4]) or the assessment of economic promotion mechanisms for RES, which depend on the match between supply and demand, cannot be supported with mere GIS-based spatial models. Therefore, the full integration of the temporal component in existing GIS-based analyses is a necessary further step [19].

In this paper, we review GIS-based spatial and spatiotemporal models and methods for the estimation of RES potentials as well as for the determination of energy demand. Based on this review, we present a methodology that integrates GIS-based RES potential assessment procedures with models for the estimation of energy generation and consumption profiles in a high temporal resolution. This new method should overcome deficiencies identified in previous approaches and contribute to decision making in integrated spatial and energy planning at the municipal scale. The research was carried out in the Doctoral project "Spatiotemporal modelling for renewable distributed energy generation planning for municipalities" and represents the framework thesis of the cumulative dissertation.

This document is structured as follows: derived from an analysis of the state of the art of spatial and spatiotemporal modelling for planning renewable energy systems in the "Theory framing and state of the art" section, a new spatiotemporal modelling and analysis approach is presented in the "Methodology" section. The results of multiple case studies as well as the strengths and weaknesses of the presented methodology are discussed in the "Results and discussion" section, and the "Conclusions" section draws conclusions.

\section{Theory framing and state of the art \\ Decision making for the energy transition}

In consonance with Fürst and Scholles [20], decision making in planning processes means connecting the factual and the value level, which is according to Scharpf [21] influenced by power relations and actor constellations. Furthermore, decision making concerning the energy transition impacts all levels of government and has to lead to a consistent action of private households and enterprises. As Stoeglehner and Narodoslawsky [22] point out, planning for the energy transition is inspired by climate protection objectives of global environmental policy; is transferred into environmental policies, energy policies, and economic policies on the national and regional level; and ends up in decisions of households and enterprises. Those are normally driven by social criteria (like prestige), economic criteria (like affordability or lowest price) and, only partly if at all, by environmental issues. Yet, all decisions on all levels, in accordance with different motives, have to point in the same direction. 
This is already challenging for inter-sectoral policymaking and administrative decisions, but even more complex when private household and enterprise based implementation of single measures is required. In order to fulfil this task democratically and de-centralized, not only governmental policies are needed, but a change in behavioural and investment patterns of numerous and highly diverse actors and stakeholders concerning their specific energy demand and supply is indispensable. Therefore, planning and implementing the energy transition can be perceived as a huge learning task for societies, which corresponds to the concept of spatial energy resilience $[23,24]$, where the resilience is not only defined as a set of physical criteria an energy system should fulfil, but where adaptive capacity and ability to learn are major societal criteria to build resilient renewable energy systems.

So far, there is no historic showcase that demonstrates how to implement a global environmental policy such as the energy transition on a regional scale. Thus, uncertainty is high: (1) technological development for energy generation, distribution and storage is still in progress, and not all technologies needed for the energy transition are already available; (2) economic framework conditions and price frameworks for a fully renewable energy system are hardly predictable; (3) how the integration of decentralized and central technologies and infrastructure networks might work is not established neither technologically nor organisationally or economically; (4) decentral decision making by a multitude of actors means that the optimal own decision largely depends on the decisions of others and optimization takes place when decisions are synchronized; (5) the optimal renewable energy technology investment largely depends on the temporal energy demand patterns and temporal resource availability in a certain spatial context, especially a municipality or region. Still, with the available technologies and under the existing economic and regulatory frameworks, a lot of measures can be taken towards the energy transition.

Such limitations call for a new generation of decision making models and tools that increase the ability of local and regional communities and decision makers to learn about these complex issues. On the one hand, this includes making system interrelations between spatial structures, energy demand, RES and technological energy supply options visible. On the other hand, learning about values, attitudes and objectives and the perceived impacts of planned measures should be supported, so that learning loops between visions, measures and their impacts allow for decisions promoting the energy turn [8].

Such decision making models are especially important for optimizing decentralized energy systems in certain spatial contexts by connecting different infrastructure systems with each other in order to optimize energy use, energy efficiency, renewable energy supply and storage capacity. For instance, electricity from volatile renewable energy sources like wind and PV power can be used to generate heat and cold with heat pumps [25] and distribute them in district heating and cooling grids, load batteries of electric vehicles or technical installations or feed it in larger electricity grids if available. The options for such optimisations are to a large extent determined by the local and regional spatial structures such as the presence of different land uses and their density, e.g. of residential, commercial, industrial land or public amenities as well as the distance and availability of transport infrastructures and energy grids as well as the temporal patterns of energy demand and supply. In order to support this optimisation, spatiotemporal modelling has become an emerging research field in the last 10 years. In the next sub-sections, a comprehensive literature review is presented as basis for proposing a holistic decision support method to operationalize spatiotemporal modelling for the optimisation of energy systems on a municipal scale.

\section{State of the art}

In order to identify GIS-based spatial models and methods for the estimation of RES potentials and the determination of energy demand, a comprehensive literature review has been conducted. This review categorises studies in three subsequent levels. Firstly, methodologies for assessing RES-based systems and estimating energy demand are divided between merely spatial and spatiotemporal approaches. Secondly, models for RES-based systems are classified as far as possible depending on the type of RES, and demand models are classified subject to the type of energy. Thirdly, models and methodologies for the RES types that constitute the focus of this paper (wind and solar power) and for energy demand are introduced following the schema shown in Fig. 1. These models span from the continental to the neighbourhood scale in spatial resolutions ranging from coarse (several kilometre) to very high (below a metre).

\section{GIS and renewable energies}

GIS have become a common tool to evaluate potentials of all types of renewable energy sources and combinations of them. Already in the early 1990s, GIS were starting to be recognized as important tools for regional planning related to RES [26]. Assessments of biomass, wind and photovoltaic energy generation potential conducted with GIS started appearing during these years [27-31]. Furthermore, the number of studies has rapidly increased in the last 10 years. As presented in Fig. 2, the amount of documents indexed in Scopus (database widely used in scientometric analysis, also in the case of GIS science [32]) that included GIS and "renewable 


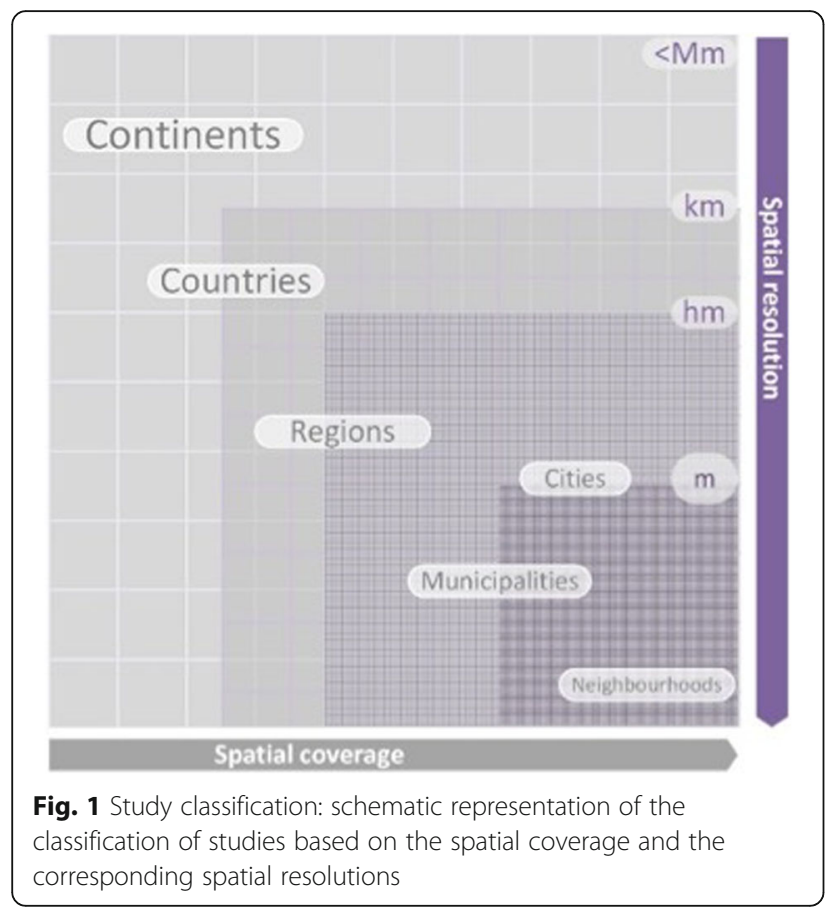

energies" in the title, abstract or the keywords grew from one or two manuscripts per year in the 1990s to 114 in 2017 and a cumulative total of 816 publications by the end of that year. Similar trends are observable when combining GIS with "biomass energy", "wind energy" and "solar energy". The latter combination is the largest one with 620 publications in total and also the only one with more than one publication prior to 1990. For instance, in 1986, Ritter [33] already proposed a simplified algorithm to calculate slopes and aspects from digital elevation models (DEMs), which contributed to facilitate calculations of solar radiation in raster data sets. Further
RES such as geothermal or tidal energy are also widely studied with GIS approaches (see [12]), but these are beyond the scope of this work.

GIS and biomass Estimations of biomass are highly diverse in terms of information source and the type of biomass that are investigated. Information sources include satellite imagery [34, 35], inventory data [36, 37], Light Detection and Ranging (LiDAR) and other remote sensing methods [38-41]. These are used in assessments of dry biomass, wet biomass and biogas, which normally aim at finding optimal locations for biomass-based energy generation plants. Studies of dry biomass include wood from forests, agricultural scraps and industrial and urban untreated wood residues [42-44], as well as cotton-stalk, switchgrass and further short rotation woody crops [45-47]. The sources of wet biomass and biogas include non-woody biomass [48] and livestock units $[49,50]$. Since the dispatch from biomass-based energy generation plants is controllable, research emphasis has been conferred to the optimal location and sizing of these energy generation plants based on economic factors and the proximity to biomass sources. The definition of these optimal locations relies mainly on the spatial (and not the temporal) availability of biomass and has been largely performed with mathematical programming and agent-based modelling approaches [51-55].

GIS-based spatial studies of fluctuating renewable energy sources Analogously to biomass-related studies, there are also multiple methodologies to determine, map and assess wind and solar energy resources. Established data sources include in situ measurements combined with statistical methods, satellite imagery, numerical

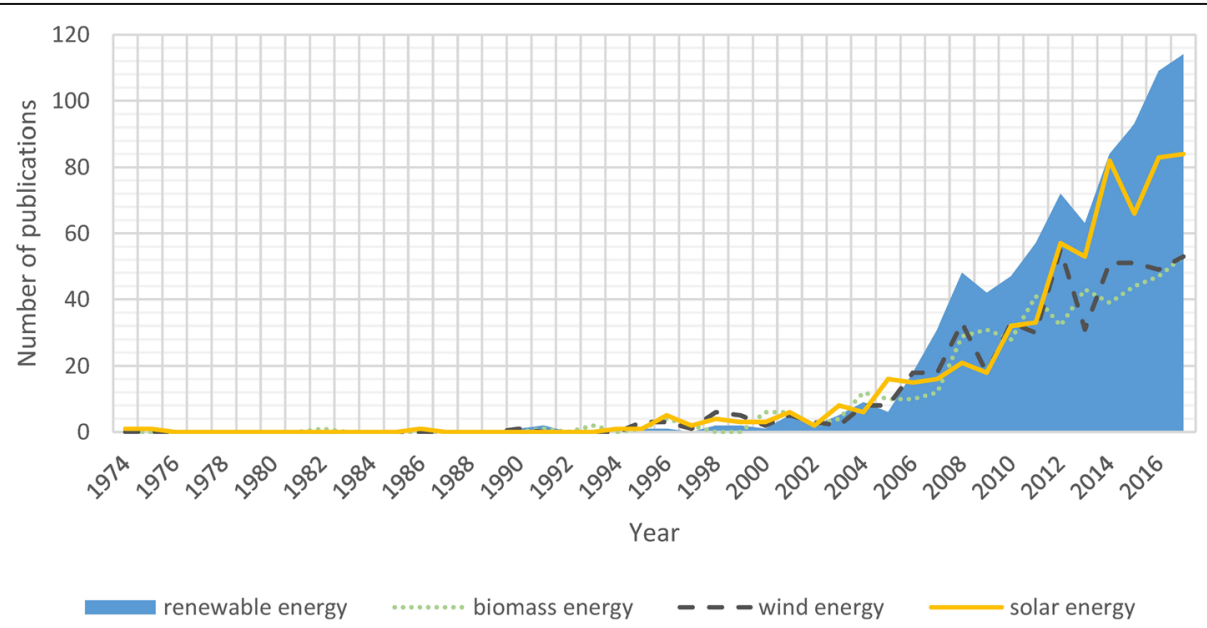

Fig. 2 GIS and renewable energies: search results in Scopus for articles including the word GIS in combination with either renewable energy, biomass energy, wind energy or solar energy in title, abstract or keywords 
weather prediction models and combinations of them $[12,56]$. These data, which are available in high temporal resolution, are usually summarized into average wind speeds and cumulative global solar irradiation per year or per month in order to generate wind and solar cadastres, respectively. Such presentations of information are ideal to determine hot spots of resource availability and to select the best locations for installations that generate as much energy as possible. When these resource availability maps are integrated in GIS, it is possible to combine the maps with multiple technical, economical and regulatory parameters in order to estimate deployment potentials of PV installations [57-61] or wind parks [62-69].

Solar energy resources, photovoltaic and solar thermal systems potential Concerning merely spatial assessments of solar energy, GIS have been extensively used to assess rooftop-mounted and free standing solar energy installations. Freitas et al. [70] reviewed 21 tools that serve to model solar energy potential in the urban environment. Tools such as the solar analyst of the proprietary GIS software ArcGIS [71] or r.sun of the open-source GRASS-GIS platform [72] have been utilized to develop a large number of cadastres for photovoltaic and solar thermal systems for locations all around the globe [70,73]. These tools serve to calculate theoretical solar radiation potentials based on geographic and geometric parameters such as latitude, longitude, altitude, aspect and slope of surfaces and further basic parameters to account for the atmosphere $[74,75]$. This theoretical calculation corresponds to the solar radiation under clear-sky conditions. In order to calculate solar radiation estimations under real-sky conditions, the tools include the possibility of integrating measured data to indirectly consider clouds and improve the solar irradiation prediction. The calculation of the effect of shadowing of near and distant objects using DEMs is also possible, and one of the major assets of GIS-based calculation methods, particularly when studying mountainous territories [76] or urban areas [77], in comparison to studies based solely on satellite imagery. For instance, Martínez-Durbán et al. [78], Bosch et al. [79], Ruiz-Arias et al. [80], Haurant et al. [81] and Ramirez Camargo and Dorner [82] have shown that significant improvements can be achieved in the estimation of solar resources when the resolution of satellite images is increased and shadowing is considered using high-resolution DEMs.

There are not only multiple GIS tools to support assessments of solar energy resources but there is also a wide range of methodologies that have been used to approach the topic for diverse study areas in different spatial resolutions. At continental and country scale, it is possible to find studies with spatial resolutions that range from several square kilometres to $90 \mathrm{~m} \times 90 \mathrm{~m}$. Šriri et al. [57], pioneers of the uses of GIS for the generation of continent-wide solar radiation, combined r.sun with measurements of 566 ground meteorological stations to generate a database of yearly and monthly solar radiation maps with a spatial resolution of $1 \mathrm{~km} \times 1 \mathrm{~km}$ for Europe. These data, together with temperature data, served to estimate PV electricity generation for every country in the continent. The resulting PV potential database was made available through the PV-GIS Internet platform of the European Joint Research Centre [83]. Almost a decade later, due to massive improvements in data availability, Huld and Amillo [84] were able to generate a database of PV potential maps for Eurasia and Africa. They used satellite imagery-derived solar radiation maps, instead of in situ measurements (the stations net is not as dense as in Europe), to calculate real-sky solar irradiance from clear-sky GIS-derived solar irradiance maps. This database includes more detail in the calculation of PV potential by accounting for the effects of temperature and wind speeds, which were obtained from reanalysis data sets [84]. At the country level, examples include an ArcGIS solar analyst-supported potential estimation for multiple Concentrated Solar Power (CSP) technologies for Oman in $3 \mathrm{~km} \times 3 \mathrm{~km}$ spatial resolution [85]; a technical and economical assessment of the potential of rooftop PV and solar hot water systems (SHW) for every municipality in Spain, which was performed using in situ data and geostatistics [86, 87]; the monthly and yearly solar radiation maps with province resolution for Indonesia generated with neuronal networks and ArcGIS [88]; the solar radiation contour maps for Argentina produced with geostatistical methods [89]; and the Chilean solar explorer [90]. The last one is a platform similar to the European PV-GIS, but in this case, satellite imagery-derived solar irradiance maps have been used instead of in situ measurements to calculate real-sky conditions. This 10 years younger online platform, which serves to interactively estimate PV electricity yield potential, has also a much higher spatial resolution $(90 \mathrm{~m} \times 90 \mathrm{~m})$ than its European counterpart [90].

While at continental and country level, the spatial resolution of the used solar radiation maps does not exceed $90 \mathrm{~m} \times 90 \mathrm{~m}$ and the standard is a resolution lower than $1 \mathrm{~km} \times 1 \mathrm{~km}$; at regional and district scale, the resolution of the underlying spatial data can be classified as coarse if it is around $90 \mathrm{~m} \times 90 \mathrm{~m}$. The spatial resolution at these scales can be below $1 \mathrm{~m} \times 1 \mathrm{~m}$. High resolutions are achieved by either estimating suitable areas for the deployment of solar systems in a high resolution, which are combined with solar radiation data in coarser resolution, or by calculating solar radiation itself in a high spatial resolution. 
The first alternative for generating high-resolution solar radiation maps is usually performed with building footprint vector data or high-resolution digital orthophotos (DOPs) combined with image classification and object recognition methodologies. Wiginton et al. [59] are pioneers in the use of high-resolution DOP for the quantification of rooftop suitable areas for the deployment of PV systems. They used both building footprints vector data and a feature analyst extraction software on $20 \mathrm{~cm} \times 20 \mathrm{~cm}$ resolution DOPs to identify potential rooftop areas suitable for PV deployment in south-east Ontario, Canada. These areas were reduced by including factors such as shading, other uses (ventilation, heating/ air conditioning, dormers or chimneys) and orientation. The PV energy output was calculated for different technologies considering the yearly cumulated average solar radiation for every studied municipality as the driving factor. Consequently, the final results were presented for the municipal scale. Bergamasco and Asirani [91] followed a similar approach for calculating PV deployment potential for Turin in Italy. They used building footprints, high-resolution DOPs and an image recognition algorithm to identify suitable rooftop areas, but instead of average solar irradiation data for the whole municipality, they utilized solar irradiation data in $1 \mathrm{~km} \times$ $1 \mathrm{~km}$ resolution available in PV-GIS. Bergamasco and Asirani [92] have also already calculated the potential of different PV technologies for the Piedmont region in north-western Italy using PV-GIS data. For this larger region, they used only cadastral data and no high-resolution DOPs. Their final PV potential results are, as in [59], cumulated to the municipal scale. Further examples of a similar approach include the work of Schallenberg-Rodríguez [93], where the techno-economical PV potential for the Canary Islands was calculated, and the work of Sánchez-Lozano et al. [94] that combined cadastral data (not for every building but for every plot), solar radiation data, average temperature and environmental, geomorphological and location factors in a multi-criteria decision making method to determine optimal locations for PV deployment in the area of Cartagena in Murcia, Spain. One step forward of the methodology of Wiginton et al. [59] is proposed by Nguyen and Pearce [95]. They analysed PV potential for Kingston in Ontario, Canada, at grid feeder resolution by also considering connectivity restrictions of the grid. In order to do that, they employed spatial data of the electric grid and a more detailed simulation of the PV energy yield. The latter was performed with the proprietary software PVSyst. Jo and Otanicar [96] proposed a related and more detailed, but also more restricted methodology to estimate PV energy yield of buildings in the metropolitan area of Phoenix, USA. They used multi-spectral and panchromatic images from the QuickBird satellite with a resolution of $0.6 \mathrm{~m} \times 0.6 \mathrm{~m}$ and object-based image identification (OBIA) to identify potential suitable surfaces for PV. These potential suitable areas were reduced depending on shadowing, which was calculated with a 3D model of the buildings and Google's SketchUp. For the estimation of the PV yield, they used the RETScreen software, which works with a mix of in situ-measured and satellite imagery-derived solar radiation data. However, they made the detailed calculation only for one specific building type and extrapolated it to all considered buildings of the same type in the study area. This fact limits the use of the methodology to only buildings with similar use (commercial and governmental) and architectural characteristics (flat roofs) [96].

The second alternative for generating high-resolution solar radiation maps, which consist of the direct estimation of solar radiation in a high spatial resolution, relies mainly on LiDAR data, photogrammetric point clouds and buildings footprint vector data with height information for the generation of DEMs of high spatial resolution. These DEMs, either in form of digital terrain models (DTM) or digital surface models (DSM), are the basis to generate solar radiation maps using GIS tools. Examples can be found for locations all around the world. For instance, Kryza et al. [97] presented a remote location example by using r.sun and a $10 \mathrm{~m} \times 10 \mathrm{~m}$ DEM to estimate solar radiation in Wedel Jarlsberg Land, Svalbard, Norway (North Pole). Examples of the estimation of active solar energy systems potential at the regional and municipal level that show the evolution in terms of methodologies and spatial resolution include: Firstly, the work of Sun et al. [98] for the province of Fujian in China. They generate monthly and yearly cumulated maps of clear-sky solar radiation using a DEM of $90 \mathrm{~m} \times 90 \mathrm{~m}$ resolution and the ArcGIS solar analyst. This theoretical potential is constrained by geographical, technical and economical parameters. Given that they examined a relatively large area and not all the considered parameters were available in the same spatial resolution, they reduced the resolution of the results to $5 \mathrm{~km} \times 5 \mathrm{~km}$. Ludwig et al. [99] used LiDAR data to generate a $1 \mathrm{~m} \times 1 \mathrm{~m}$ DSM, which was combined with building footprints to provide a detailed rooftop PV potential cadastre for the City of Osnabruck in Germany. These authors implemented their own shadowing and radiation algorithm and considered homogeneous parts of the rooftops in terms of yearly cumulated solar irradiation as suitable surfaces for PV deployment [99]. They further reduced the amount of potential areas by excluding surfaces with a size below the threshold of typically profitable PV installations [99]. Similarly, Kodysh et al. [100] employed LiDAR to generate a $1 \mathrm{~m} \times 1 \mathrm{~m}$ DSM for the Knox County, Tennessee, USA. They used this 
DSM as input for the ArcGIS solar analyst and calculated monthly average days of solar irradiation to develop a cadastre of total yearly solar irradiation. These authors dedicate a significant part of their methodology to the issues of working with a large data set (the $1 \mathrm{~m} \times$ $1 \mathrm{~m}$ DSM of the Knox County had a size of more than $10 \mathrm{~GB})$. Their solutions were to divide the study area in multiple tiles to be handled separately for the calculation and then to consider only the buildings' roofs and a buffer of $25 \mathrm{~m}$ for the calculation of shadowing and solar irradiation. Both Hofierka and Kaňuk [77] and La Gennusa et al. [101] combined a DTM of relatively low resolution with a vector data set of the building footprints with height information to generate a DEM of $1 \mathrm{~m} \times 1 \mathrm{~m}$ resolution for Bardejov (Slovakia) and $\mathrm{Pa}-$ lermo (Italy), respectively. Hofierka and Kaňuk [77] used r.sun with PV-GIS data to calculate real-sky solar radiation and PV potential for the study area. They performed a coarse calculation and estimated that PV could cover $2 / 3$ of the city's electricity demand. La Gennusa et al. [101] made emphasis in the calculation of suitable roof surfaces for the installation of PV and solar thermal systems. They made assumptions about the tilts of the roofs (since in the generated DEM all roofs are flat) and estimated shadowing in order to reduce the suitable roof areas [101]. The potential energy yield of the remaining areas was calculated using data from the PV-GIS platform [101]. Brito et al. [102] combined LiDAR data and photogrammetric methods to generate a $1 \mathrm{~m} \times 1 \mathrm{~m}$ DSM of a part of Carnaxide, Oeiras, Portugal. They performed the clear-sky solar radiation calculation with ArcGIS solar analyst and approximated real-sky conditions with PV-GIS data. They calculated rooftop PV energy generation potential using a simple formula based on the total energy irradiation in every pixel and a factor to account for typical PV system efficiency [102]. Nguyen and Pearce [103] appealed to LiDAR data of a part of downtown Kingston, Ontario, Canada (with 100 buildings) to generate a $0.55 \mathrm{~m} \times 0.55 \mathrm{~m}$ DSM of the roofs. These authors tested the capability of r.sun to deal with different levels of complexity. They used r.horizon to speed up the solar radiation calculation and evaluated the differences in the results due to DEM resolution, presence or absence of shadows and temporal granularity of the estimation. Agugiaro et al. [104] examined the solar radiation potential and created a WebGIS platform for evaluating PV potential of a $2.5 \mathrm{~km} \times 2.5 \mathrm{~km}$ part of the Alpine city of Trento (Italy). They used a LiDAR-derived $2 \mathrm{~m} \times 2 \mathrm{~m}$ DTM and $1 \mathrm{~m} \times 1 \mathrm{~m}$ DSM together with local imagery and advanced automated image matching methods to generate a $50 \mathrm{~cm} \times 50 \mathrm{~cm}$ resolution DSM of the study area. r.sun was employed to calculate average yearly values of global irradiation. In their proposed methodology, the first step was to calculate clear-sky daily sums of solar irradiation and then to adjust the values to real-sky conditions with the aid of 7 years of measurements obtained from a pyranometer installed on a building in the study area.

One of the major limitations for calculating high spatial resolution solar radiation maps is the required computational capacity. The concern was made evident already in studies $[99,100,103,104]$, where the study area was constrained to few square kilometres, or the calculation of solar radiation was performed only for specific parts of the study area, or the input DEMs were divided in tiles, or the temporal granularity of the calculation of solar irradiance was kept coarse. Lukač and Žalik [105] showed that one alternative to deal with this issue is the use of general purpose programming on graphic processing units (GPGPU) to perform the solar radiation calculation. They implement a solar radiation estimation algorithm to be run on a graphic processing unit (GPU) and quantify its advantages against single central processing unit (CPU), and parallel multi-CPU implementations. For the quantification, they used LiDAR-based $1 \mathrm{~m} \times 1 \mathrm{~m}$ DSMs of a $0.73 \mathrm{~km}^{2}$ area of Pekre and a $1.27 \mathrm{~km}^{2}$ part of Maribor city in Slovenia. This was employed together with a lower resolution DTM $(25 \mathrm{~m} \times 25 \mathrm{~m})$ for $315 \mathrm{~km}^{2}$ of the territory around the study areas in order to account for the shadowing of distant objects. In order to calculate real-sky values, they utilized pyranometer records of one decade. The same team continued working with this approach and the study area of Maribor. In [106], they extended the methodology to select surfaces of the roofs that are best suited for PV systems. In [107], these authors improved the PV energy yield estimation by including non-linear efficiencies for the PV modules and inverters. A similar approach is followed by Huang et al. [108]. They implemented the SHORTWAVE-C algorithm using GPGPU to estimate rooftop solar radiation potential for a study area in Shanghai, China.

Another field of development that has gained attention in the last years is the calculation of solar radiation and PV potential on building facades. This however requires even higher computational capacities and high-quality $3 \mathrm{D}$ data sets that are not widely available [70]. First studies in this field include Redweik et al. [109] who described a model to calculate solar radiation on rooftops and facades based on DSMs constructed with LiDAR data. The authors conducted a case study with a $1 \mathrm{~m} \times$ $1 \mathrm{~m}$ resolution DSM of the campus of the University of Lisbon, Portugal. Posteriorly, the same authors presented the integration of these data in a 3D building model in a GIS for optimized querying of PV energy generation potential of individual surfaces (rooftops or facades) and buildings [110]. Jakubiec and Reinhart [111] proposed a methodology where a detailed Daysim reverse raytracing 
simulation is performed for every single surface of a 3D model that is generated from LiDAR. The solar irradiance data is then used in a PV model that considers ambient and surface temperature in addition to typical technical factors such as PV panels and inverter efficiencies. They tested the methodology with data from Cambridge Massachusetts and made summarized information available through a public WebGIS tool. This is probably the most detailed and precise photovoltaic potential map of a city available today. However, the required computational capacities are considerably higher than the ones that would be necessary if other GIS-based tools such as ArcGIS solar analyst or r.sun would have been used to estimate the solar radiation [111].

Wind speeds, energy and wind parks GIS have been also largely used in the planning process of wind parks. Average wind speed, dominant wind direction, slope of the terrain, accessibility (appropriate roads for the transport of infrastructure) and visual impact are parameters that have been usually examined using GIS to construct wind atlases and to determine optimal locations for wind parks [12]. Studies variate, among others, in spatial coverage, spatial resolution, the type of technology that is assumed, and the methodology and data source for the estimation of wind availability. Data sources comprise in situ measurements from meteorological towers, reanalysis data sets and satellite imagery (the latter one for off-shore wind potential estimation). While in situ measurements are considered the most accurate data sources, their spatial coverage is limited. Conversely, reanalysis data have global coverage but they are not necessarily an accurate source for punctual wind resources estimations [112] (the spatial resolution is still above several kilometres).

Methodologies for generating wind atlases in the desired resolution and coverage include geostatistical methods, computational fluid dynamic models, numerical atmospheric mesoscale models and combinations of them. For instance, Hoogwijk et al. [113] estimated global technical and economical wind energy potentials in a $0.5^{\circ} \times 0.5^{\circ}$ spatial resolution. These authors consecutively reduce the theoretical wind energy generation potential per pixel by applying geographical (wind regime, altitude, urban areas, land-use), technical (extrapolation of the wind speed to hub height, amount of full-load hours) and economic (regional cost-supply curves) restrictions. They determined the wind regime using the average wind speed maps generated by the Climate Research Unit, which were generated using geostatistics and in situ measurements [114]. Himri et al. [115] evaluated the availability of wind resources in terms of average wind speed, wind power density, predominant wind direction frequency distribution and Weibull distribution parameters for Algeria by using geostatistics and 3 years of in situ measurements data. An example that shows the evolution of the methodologies is the case of the Swiss wind atlas. The first Swiss wind atlas constructed in 2004 relied on in situ measurements and geostatistics while the last version was calculated with the Computational Fluid Dynamics - Modell implemented in the software WindSim [112]. This allowed to generate monthly and yearly maps of average wind speed with a spatial resolution of $100 \mathrm{~m} \times 100 \mathrm{~m}$ for five different heights $(50 \mathrm{~m}, 75 \mathrm{~m}, 100 \mathrm{~m}, 125 \mathrm{~m}$ and $150 \mathrm{~m})$ and a higher accuracy compared with the previous Swiss wind atlas [112]. Nowadays, such high-resolution atlases can be found for locations all around the globe and are generated also with alternative methodologies such as atmospheric mesoscale models. Examples include the $3 \mathrm{~km} \times 3 \mathrm{~km}$ wind atlas of Thailand [67] and the British Islands [116], the $100 \mathrm{~m} \times 100 \mathrm{~m}$ Austrian [117] and Bavarian [118] wind maps and the microscale $90 \mathrm{~m} \times 90 \mathrm{~m}$ wind map of the Phaluay Island (Thailand) [68]. In all these cases, reanalysis data such as the ERA-40 [119] or the ERA-INTERIM [120] of the European Centre for Medium-Range Weather Forecast (ECMWF) or the Climate Forecast System Reanalysis (CFSR) of the National Centres for Environmental Prediction (NCEP) [121] are brought to a higher spatial resolution using atmospheric models such as the Karlsruhe Atmospheric Mesoscale Model (KAMM) or the Weather Research and Forecasting model (WRF).

\section{GIS and energy demand}

GIS-based estimations of energy demand for electricity, heating, cooling and warm water can be traced back almost two decades, and the number of studies had increased considerably in the last years. A Scopus search for the words GIS combined with "energy demand" in the title, abstract and keywords delivered 611 results that are distributed between 1975 (1) and 2017 (85). Due to the high energy demand and the corresponding high potential for energy savings, the residential building sector has attracted special attention. Already in 2009, Swan and Ugursal [122] and in 2010 Kavgic et al. [123] reviewed more than a hundred original research articles (when counting the references of both publications and avoiding repetitions) dedicated to the estimation of energy demand, mainly for heating, for the residential building sector. While a handful of these articles used GIS for data retrieving, management and visualization, Reinhart and Cerezo Davila [124] showed that it is mainly in the last years that GIS became an essential tool to estimate energy demand of neighbourhoods, cities and municipalities. 
Similar to the GIS-based studies of renewable energies, GIS-based studies of energy demand are available for different types of energy in resolutions that range from continental to neighbourhood scale.

Continental to regional scale One of the first studies that could be found for a large area is the GIS-based estimation of energy demand for water heating by Voivontas et al. [125]. This study was performed as part of an economic assessment of solar water heating systems for the residential sector at the municipal level for Greece. A case study that has received considerable attention is the Danish building stock. For instance, Möller and Lund [126] generated a heat atlas to study the potential of expanding district heating networks in this country. They used the national register of buildings and dwellings, address locations of every building and 175 building typologies (25 sub-types and 7 age classes) as input for a physical heat demand model to calculate yearly energy demand for heating and warm water for the whole Danish building stock. The atlas is the input for the energy system analysis model (EnergyPLAN) to evaluate the potential of district heating for replacing other heat energy generation technologies. Petrovic and Karlsson [127] also calculated yearly energy demand for heating and warm water of the Danish building stock. They used a physical model based on monthly calculations of heating days, heat losses and heat gains together with a typology approach that divides the Danish building stock in 360 groups. The yearly energy demand estimation is performed for every building and served as input to evaluate heat saving energy potentials at the national level.

In contrast to the use of physical bottom-up models for the Danish case, where the building stock is relatively small and there is a reliable building register, the studies for larger building stocks with unreliable or inexistent building registers tend to rely on statistical top-down approaches. Gils et al. [128] used statistical data to calculate energy demand for heating and hot water of the US building stock (residential and commercial) in order to evaluate the possible role of district heating in the country until the year 2030. They determined the average annual per-capita heat demand on the basis of statistics and projections of the total final energy demand. These values were distributed through the country using population and land use data. The results were summarized to state and census region levels for the district heating potential analysis. Connolly et al. [129] employed a procedure similar to the one of Gils et al. [128] to calculate heat demand per capita in the case of the EU. This demand was spatially distributed using the GEOSTAT European population raster data set with $1 \mathrm{~km} \times 1 \mathrm{~km}$ spatial resolution and adjusted to local climatic conditions using the European Heating Index (EHI), which has the same resolution as the third level European administrative units (NUTS3). These authors used the estimated energy demand data to appraise the potential of district heating and heat savings to decarbonise the energy system of the EU.

There are also GIS-supported studies at country and continental levels that focus on electricity and energy demand for cooling. Research related to electricity demand usually relies on statistical approaches to spatially distribute country-wide energy demand data in municipalities or regions. Such studies are nowadays common for countries with low level of electrification where the interest is to compare scenarios of grid extension against the installation of off-grid systems [130, 131]. Energy demand for cooling is a topic that is gaining more and more attention due to the expected climate change-related temperature rise [132, 133]. In the same way that heating days and degree heating days are used as input for physical models to estimate energy demand for heating, cooling days and degree cooling days are necessary to estimate energy demand for cooling. Chiesa and Grosso [134] and Petri and Caldeira [132] present examples of calculation of these indicators for the cases of the Mediterranean area and the USA, respectively. In the case of the study of the Mediterranean area, punctual data in specific locations of the study area are used, while in the study of the USA, the authors utilized numerical weather models to provide an estimation with full spatial coverage. A further example is the work of Sakaguchi and Tabata [135], who made a spatial explicit distribution of yearly electricity demand of Awaji Island in Japan. The authors proportionally distributed the official values of total electric and heat energy consumption of the island based on the participation ratios of manufactured shipment (to account for the manufacturing sector), number of employees (to account for agriculture, forestry, fishery, construction, mining and service sectors) and number of households of every city (to account for the residential sector). They evaluated the possibilities of the island achieving 100\% electric power provision from PV, wind power and biomass.

Regional to neighbourhood scale At regional to neighbourhood scale, the use of a typology approach for distributing energy demand in space is the predominant trend. In this approach, the building stock is divided into typologies and a typical energy demand per unit area is attributed to every building depending on the typology this building belongs to. The differences in studies are mainly related to the source of the typical energy demand values of the typologies. There are studies relying on survey or in situ-measured data and energy demand values reported in the literature [136-140] or on physical building models [141-146]. 
As example of the first group, Dall'O' et al. [136] studied a medium-size town in the Italian region of Lombardy, where the typical energy demand values were based on energy audits of a sample of buildings. Similarly, Delmastro et al. [137] relied on measured demand data of 288 buildings in Turin to calibrate a linear regression model for different construction periods of the buildings. These models predicted primary energy need for space heating as a function of the surface to volume ratio and were used to estimate the energy demand of 21 buildings corresponding to different construction periods, this with the aim of planning an optimal district heating network. Following the same principle, Baker and Rylatt [138] combined energy demand data obtained from an extensive survey and GIS analysis, to estimate heating areas of buildings. These heating areas were employed to generate clusters of consumer types for parts of the city of Leicester and Sheffield in the UK.

In the particular case of Bavaria (Germany), it is already possible to find an extensive list of case studies of heat demand cadasters produced with energy demand values reported in the literature. This German state launched a manual for the realization of energy use plans for municipalities in 2011 [139]. To estimate yearly energy demand for heating and warm water, the manual proposes two different methodologies based on typical energy demand values published by the German Institute for Housing and Environment (Institut für Wohnen und Umwelt-IWU) [147]. In the simplest methodology, municipalities are separated into settlements that are characterized by the most common building. The energy demand for heating and warm water for every area unit of the settlement is the same of the most common building, which is defined in one of fifty possible building typologies (40 residential and 10 non-residential). In the most detailed procedure, every building is classified into one of the typologies and the energy demand values of the typology are assigned to the building. The classification into typologies is based on construction year, number of storeys and number of households for the residential case. For non-residential buildings, the classification is based on the use of the building, the number of employees, number of beds (for hospitals), number of pupils (for schools and kindergartens) or the area of heated pools (for swimming pools). Fixed rates are discounted to the energy demand indicators of a building if there is information available about retrofitting measurements. The resulting maps are used to recognize yearly energy demand hot spots and evaluate the potential of retrofitting measures in the buildings stock or for the estimation of the suitability of district heating networks.

Stoeglehner et al. [140] adopted an approach where measured energy demand data are combined with energy demand values reported in the literature. These authors relied on energy demand data obtained from an extensive survey for commercial, industrial buildings and a part of the residential users. Additionally, they utilized information of the national building dwellings and buildings registry of Freistadt in Austria to classify residential buildings, without information from the survey, into typologies defined by Mitter [148]. The energy consumption values for heating and hot water and the estimated heated area of the buildings were used to estimate total energy demand for each building in the municipality. Moreover, two retrofitting scenarios were proposed, one where energy demand reductions of $20 \%$ are achieved and other where these reductions reach $50 \%$. Based on these data, these authors developed an ArcGIS-based tool called "Energiezonenplanung" (energy zones planning - EZP) that cumulated the energy demand of buildings per street in order to build energy zones, which could be linked with a district heating network. The tool calculated the heat demand density per metre of district heating network for different possible network shapes and under the different building retrofitting scenarios. This indicator served to determine the economic viability of such infrastructure in every case.

In the second group, the studies rely directly on a physically based model of the energy use of buildings. Gadsden et al. [141] proposed a methodology called "solar energy planning" (SEP) for the residential building stock of the UK. The core of the methodology is the monthly version of the Building Research Establishment Domestic Energy Model (BREDEM-8[149]). This two zones model is able to estimate energy consumption in dwellings in terms of space heating, water heating, lighting, electrical appliances and cooking. Basic input data can be estimated from the shape and age of the dwelling. The building stock is divided in six main classes (detached, semi-detached, end terrace, mid-terrace, mid-terrace with unheated connecting passageway and flat). GIS is used to obtain basic geometric information of the buildings and to display the results. The methodology is theoretically usable for entire cities, but only one application example for a small part of Leicester was found in [142]. Yu et al. [143] forecast energy demand at tax lot scale for a new planned district in the Yongding county in China. Buildings were classified into typologies, and energy demand for heating and cooling per room conditioned area were calculated using the engineering simulation software from the US Department of Energy, eQuest. The authors used a Bayesian model to calculate the energy demand per tax plot with the aim of determining the potential of water source heat pumps and CHPs at this scale. Vettorato et al. [144] conducted a case study with data of an alpine municipality (2700 inhabitants and 1400 buildings) located in Trentino, Northern Italy. Energy demand for heating was 
computed based on energy losses through transmission and ventilation. The energy losses due to transmission were approximated using the differences between external and internal temperatures and building insulation parameters while the energy loss due to ventilation corresponded to standard values. The authors summarized the building-specific energy demand data into three qualitative levels. These levels were presented in a raster map that was employed to estimate the potential exploitation of RES such as solar irradiation, ground source geothermal heat pumps, wood biomass and hydropower from drinking water systems. Ascione et al. [145] calculated yearly energy demand for heating and cooling for the historical Centre of Benneto in Italy. They simplified and adapted the seasonal calculation procedure of the European Standard EN ISO 13790. The calculation was performed for more than 500 buildings, and the results were summarized by assigning the demand of a building to a certain energy performance class. The resulting energy demand maps served to evaluate the potential of poly-generation equipment (Combine Cooling, Heat and Power-CCHP) to cover the energy demand. Similarly, Fichera et al. [146] mapped yearly energy demand of buildings, transport and outdoor lighting. They relied on the Italian version of the EN ISO 13790 to compute energy demand for heating and the energy performance index (yearly energy demand per unit of heated area) for typical buildings in different construction periods (with the same assumptions used by Ascione et al. [145]). They employed the model results from typical buildings to construct regression curves that correlated the energy performance index with the surface to volume factor. These curves were the input to estimate the energy performance index of every building in a neighbourhood (with a total area of $0.67 \mathrm{~km}^{2}$ ) of the urban area of Catania in Italy. Electricity demand per unit of build area was calculated by dividing the total electricity demand of the regional area in the census tract area. For the outdoor lighting, the number of lamps was multiplied by the power rating of each lamp and by the operation time per year. This value was divided by the area of streets and public spaces in order to obtain the yearly energy consumption per unit area.

\section{Spatiotemporal modelling for renewable energy planning}

One necessary development for GIS-based studies of RES was and still is the full integration of time in the analysis. This was already stated by Angelis-Dimakis et al. [12] and was reaffirmed by Resch et al. [19]. RES-related studies with a spatiotemporal approach were not absent until this moment but is only with recent developments in hardware and software that such studies started to grow in number. The necessity of integrating time analysis in GIS, the idea of managing spatiotemporal data sets and the description of the corresponding challenges can be traced back to the 1990s [150-155]. Spatiotemporal modelling was seen as the step forward in GIS, which would contribute to study a multiplicity of environmental, social and economic issues in a whole new way. However, there were limitations in terms of data types, software and hardware able to manage the necessary data sets and analysis. With the increments in CPU speed and storage capacities as well as with gains in popularity of parallel CPU computing, GPGPU, cloud computing and Big Data analysis tools, these limitations started to disappear in the last years. Additionally, developments in software such as spacetime [156], a package for spatiotemporal data sets for the R software platform, or TGRASS [157], a spatiotemporal database and analysis framework for the GRASS GIS software, have brought the potential of spatiotemporal modelling and analysis to a wider public. In fact, some of these developments have already found their way to studies related to RES.

Spatiotemporal modelling and analysis of RES is an emerging research field. As presented in Fig. 3, the number of publications indexed in Scopus with the words "spatiotemporal" and "renewable energy" in the title, abstract or keywords grew from a total of two publications cumulated until 2007 to a total of 262 in 2017. This development includes a significant growth trend between 2011 and 2017. Comparable trends are observable for the combinations of "spatiotemporal" and "wind energy" and "spatiotemporal" with "solar energy". The number of documents in these two cases reaches 59 and 45 publications, respectively, for the peak year 2017. Analogously to the case of GIS and "solar energy" in the previous section, documents related to "solar energy" have the longest trajectory when compared to publications related to "wind energy" or "biomass energy". As expected, in the light of the previous section, the number of publications related to "spatiotemporal" and "biomass energy" is the lowest, due to the storability properties of biomass.

Differently to the case of only spatial GIS-based studies of RES, spatiotemporal approaches tend to consider multiple technologies and energy demand at once. One of the pioneers, Biberacher [158], proposed a spatiotemporal modelling approach implemented in the software tool TASES (Time and Space resolved Energy Simulation) in 2004. This served to perform studies at the continental and global scales. TASES was utilized to investigate the requirements for complementary transmission and storage requirements in the $\mathrm{EU}$ in a scenario of high penetration of RES, to quantify the competition of PV systems based on geographical dependency and to evaluate the idea of a global electricity grid. The temporal resolution of such studies was $1 \mathrm{~h}$ covering a period of 1 year and the resolution of the 


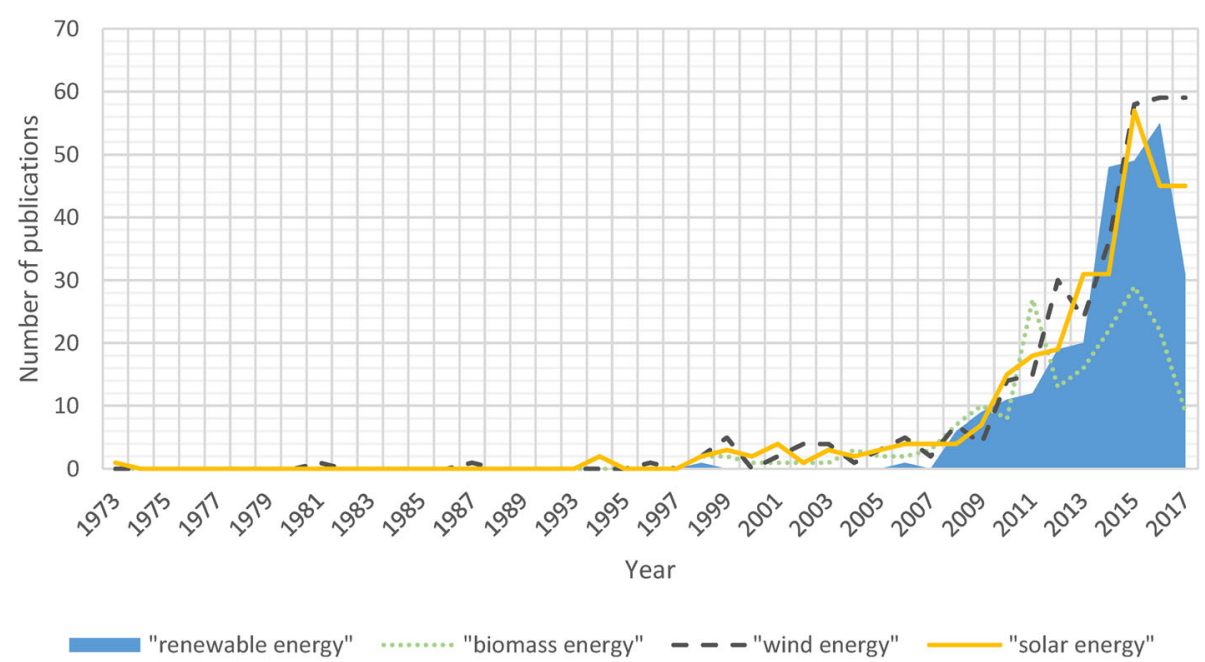

Fig. 3 Spatiotemporal modelling and renewable energies: search results in Scopus for articles including the word spatiotemporal in combination with either renewable energy, biomass energy, wind energy or solar energy in the title, abstract or keywords

input data exceeded several kilometres. The author also proposed several optimization alternatives for finding solutions for the multiple case studies. These included linear optimization and an evolutionary algorithm. Also in the proposal of a large-scale energy system but in a much newer study, Schmidt et al. [159] used time series of 34 years of reanalysis data and hydrological inflow measurements for proposing an optimal mix of solar PV, wind and hydropower for providing low-carbon electricity supply in Brazil. The reanalysis data sets had resolutions of several kilometres and a temporal resolution either of 1 or $3 \mathrm{~h}$, while the hydrological inflow data was punctual (data for every hydroelectric power plant) and had a daily temporal resolution. These authors used an optimization and a simulation model to propose possible solutions that allow high integration of RES in the Brazilian energy matrix, which at the same time improve the reliability of the energy system.

Examples at the country level for particular technologies can be found in [160], [161] and [162]. The first publication deals with the economic potential of wind power and the second and third ones with optimal deployment of photovoltaics for different types of users. In [160], potential areas for the installation of wind turbines are identified by discarding areas with spatial constraints related to the natural environment, infrastructure and regulations. The average wind speed per hour at $100 \mathrm{~m}$ height for every $100 \mathrm{~m} \times 100 \mathrm{~m}$ area is calculated for 13 years using Weibull parameters and Monte-Carlo simulation. The energy output of potential turbines is estimated with technical parameters of two different turbine types. In the case of [161], the study country, Austria, is divided into a raster grid of $1 \mathrm{~km} \times 1 \mathrm{~km}$ and PV potential as well as electricity demand is estimated for every pixel in the grid in hourly temporal resolution for an entire year. The potential PV energy yield was determined with solar irradiance data from the Climate Monitoring Satellite Application Facility and temperature data from the reanalysis of the ECMWF. In terms of technology, crystalline silicon cells mounted on free-standing racks in the angle that provides the highest output per year were assumed. Electricity demand profiles were spatially distributed using population, buildings and dwellings data in $1 \mathrm{~km} \times 1 \mathrm{~km}$ resolution. The time series were based on measured data of 800 households for residential users and on simulated stochastic load profiles for commercial users. The analysis served to identify the maximum possible PV penetration in the national energy matrix without any investments into grid enforcements. In [162], the users are self-sufficient single-family houses and an assessment of the required installed capacities of PV and Battery systems to supply such users is performed. The authors use a mixed-integer linear program (MILP) and 20 years of radiation and temperature data from the COSMO-REA6 regional reanalysis [163] to deliver maps of punctual minimum and optimal required system sizes to supply this type of users in all rural areas in Germany and the Czech Republic.

The representation of a study area in form of a raster grid (common denominator in studies from the global to the country scale) can be found also in studies at the municipal and city scale. In [164], [165] and [166], the authors proposed a top-down model to generate micro-level spatiotemporal urban energy demand profiles from macro-level input data, which is used to evaluate high penetration of RES such as wind power and PV in several city-wide case studies. They utilized a 
statistical approach to distribute energy demand for electricity, heating and cooling in a raster grid that represents the study area. Using the demand data as input, the authors evaluated the potential of deploying multi-carrier energy networks and enabling technologies such as heat-pumps, heat and electric storage systems as well as electric cars (for storage) for integrating centralized wind production and distributed PV energy generation. The proposed models had temporal resolution of $1 \mathrm{~h}$ and spatial resolutions that range between 100 and $5000 \mathrm{~m}$ (depending on the homogeneity of the city) and were used for Delhi, Shangai and Helsinki [164-167]. These case studies showed that RES penetration can only achieve $20 \%$, if no reverse flow is allowed. However, this can be increased up to $70 \%$ if short-term storage is available or interconnection between the different energy carrier grids is possible.

The change from the raster grid approach to an object-based approach (e.g. buildings) increases not only the possibilities of the analysis (e.g. individual installations can be planned) but also the amount and quality of the input data, and the required computational capacities increase considerably. These factors make the reproducibility of the analysis difficult and have limited the use of very detailed spatiotemporal models to only small groups of buildings [168], such as neighbourhoods [169] and university campuses [170, 171]. One example of a high level of detail is the work of Robinson et al. [168]. These authors proposed a comprehensive simulation of resource flows in the urban environment implemented in the software CitySim. The core of the approach is a physical thermal model to estimate energy need of buildings for heating, cooling and hot water preparation and to describe the thermal interactions between buildings. This model is complemented with radiation, behavioural, plant and equipment models. The objective was to develop a software that serves to plan a sustainable energy supply for a certain study area. Energy conversion systems included heat pumps, cogeneration systems, PV, solar thermal collectors, wind turbines, boilers and thermal storage tanks. These authors presented a case study of a group of buildings in the district of Matthäus in Basel, Switzerland. A related approach implemented in the proprietary GIS software ArcGIS is the City Energy Analyst (CEA). This was tested with data of a neighbourhood of the city of Zug in Switzerland [169]. CEA includes a physical thermal model to estimate energy need of buildings and models for rooftop solar potential (PV, solar thermal and combined systems), ambient heat (geothermal and water bodies), waste heat (servers, industrial processes, sewage), heat pumps, CHP, fuel cells and combined gas cycle turbines. Moreover, CEA incorporates optimization modules for the thermal networks and the sizing of the individual installations as well as modules to support decision making (e.g. reliability assessment and life cycle analysis) and to improve the participation processes (graphic user interface in the ArcGIS environment). The level of detail of CEA is very high and the results are manifold, but this also means a high level of detail of the input data and the necessity of high computational capacities to perform the analysis.

Another detailed approach only for PV is adopted by Kucuksari et al. [170]. They coupled GIS, CAD, mathematical optimization and detailed simulation of the grid to define optimal size and locations of PV in campus area environments. A case study of the campus of a major university in Arizona, USA, was conducted. The necessity of human intervention for checking every potential area for PV, the use of a detailed CAD model of the grid and the employment of PowerWorld simulator ${ }^{\circ}$ for simulation in a high temporal resolution make the approach very accurate but hard to extend to larger areas. Similarly, Choi et al. [171] developed the "PV Analyst", a tool for the GIS software ArcGIS, which integrates the Transient System Simulation Tool (TRNSYS) to estimate PV energy yield in a high spatial and temporal resolution. They presented a case study with a DEM of $0.31 \mathrm{~m} \times 0.31 \mathrm{~m}$ spatial resolution for 12 buildings in Pollock-Commons area at the Pennsylvania State University. They used solar analyst in ArcGIS to preselect areas where PV would receive the maximum sun hours either during the winter or summer solstice. After that, they generated PV energy yield profiles in 1-h temporal resolution for every selected section of the roofs of the 12 buildings using TRNSYS.

Also in the case of PV, the work of Lukač et al. [107] in 2014 and Jakubiec and Reinhardt [111] in 2013 (presented in the section of only GIS-based estimations of PV potential) described methodologies which were already able to generate PV potential data in high spatiotemporal resolution for entire cities, but they did not make further use of the data. It was only in 2016 that Srećković et al. [172] extended the methodology of Lukač et al. [107] to improve the evaluation of suitability of surfaces for PV. These authors included the high temporal resolution energy output of every potential surface and the electricity demand profiles of buildings in a distribution network model to assess which of the installations would lead to the highest reduction of network losses per year. Mavromatidis et al [173] employed the solar analyst of ArcGIS (with atmospheric parameters calibrated using Meteonorm data) to generate hourly radiation time series for every building roof in the Swiss village of Zernez (1,150 inhabitants and 300 buildings). These time series together with hourly demand data (constructed with modified daily electricity demand profiles of the Swiss norm SIA 2004) were the input for a mixed-integer linear program (MILP) to select optimal 
buildings' roofs for installing photovoltaic panels and optimal storage sizes based either on minimum costs or maximum integration of PV. Penetration rates of PV ranged from $25 \%$ for the minimum cost optimization to $64 \%$ for the maximum RES share case.

\section{Spatiotemporal modelling and energy demand}

The necessity of models and methodologies to estimate energy demand in a high temporal resolution is strongly linked to developments in the studies of high integration of RES. Most of the examples of the previous section already included a methodology to estimate energy demand. In the case of energy demand for electricity, studies rely on data from grid operators, standard load profiles or models for certain types of users. Top-down and bottom-up spatiotemporal models for electricity demand were used, e.g. in [161, 165, 166]. Multiple other approaches, based either on deterministic statistical disaggregation or bottom-up models, are available for the estimation of the electricity demand for the residential sector in high temporal resolution [174]. These, however, do not have a spatial reference. In the case of energy demand for heating, cooling and hot water preparation, there is also the parallel development between spatiotemporal models for demand and RES potential. This is mainly related to the assessment and planning of district heating or multi-carrier networks, which are supported by technologies such as heat pumps, solar thermal systems and CHP. Examples of the use of these models include $[145,167-169,175,176]$, and there is also a significant body of literature dedicated exclusively to these energy demand models for the urban environment.

Spatiotemporal models for energy demand for heating, cooling and hot water preparation are mainly a part of what Reinhart and Cerezo Davila [124] described as urban energy models (UBEM), Kavgic et al.[123] as "bottom-up building physics" and Swan and Ugursal [122] as "bottom-up engineering". UBEM comprise a nascent field that couples detailed individual building energy models with spatially distributed building stocks (usually divided in typologies) that range from small groups of buildings to thousands of them [124]. Not all UBEM are considered here as spatiotemporal models; since studies such as $[141,145,146]$ (described in the "GIS and energy demand" section ) used both, detailed individual building energy models and spatially distributed building stocks, but the output of the model is produced and analysed only for yearly values. Spatiotemporal models employ detailed building models to produce time series (usually hourly data) of energy demand. While there are different tools and approaches to generate these time series, most of the published work relies on a similar model to the "simple hourly calculation procedure" explained in the EN ISO 13790. This is a single zone (extendable to n-zones) thermal model defined as a five resistances one capacitance model that takes into account heat losses due to transmission and ventilation as well as heat gains due to occupancy, solar irradiation, appliances and lighting [177]. The model itself was validated in several occasions $[177,178]$ and is the core of the GIS-based procedures such as the developed by Ramirez Camargo [179] and posteriorly by Fonseca and Schlueter [180]. In both works, the EN ISO 13790 was used in combination with ArcGIS for both data management and visualization. In [179], the calculation was simplified to run with typologies data of the TABULA project (there is data available for the residential sector of several European countries) [181]; it did not consider the effects of shadowing from near objects on the solar energy gains of the buildings and was tested with thousands of residential buildings of a German municipality. Differently, in [180], the development was customized to Swiss databases, took the effect of shadows on the solar gains into account (using data generated with a modified version of the solar analyst of ArcGIS) and was tested with data of a Swiss neighbourhood. The building thermal model of Kämpf and Robinson [182], which is similar to the model the that was used in $[179,180]$, is also the core of the work of Robinson et al. [168], but these authors did not rely on ArcGIS for data management and visualization. The major challenges recognized in $[168,179,180]$ are the quality of the input data of the building stock (e.g. current level of construction quality, assumption about occupational behaviour), which can severely impact the results and the necessary computational capacities that limit the possible size of a study area, and the amount of buildings that could be studied.

The field of spatiotemporal modelling of RES potentials is only in its early development stage, and the emphasis has been given either to models for a large spatial coverage such as entire countries or to the study of small areas such as neighbourhoods. These developments are still insufficient to support the planning process of decentral energy systems for municipalities and further research is necessary: Coarse models usually available for large areas can only be used in a limited manner to evaluate individual installations in urban environments. Very high resolution approaches such as the ones used for neighbourhoods are difficult to apply to larger areas due to the necessary input data and required computational capacity. Thus, the following requirements have to be addressed: (1) the development of procedures to integrate and resample spatiotemporal data sets and models with large coverage into models for municipalities; (2) the definition of appropriate input data sources and level of detail that allow the assessment of individual RE generation installations for areas considerably larger than neighbourhoods; (3) the determination 
of a balance between UBEMS for countries and UBEMS for neighbourhoods in order to model large building stocks in detail by taking the geographic location into consideration; (4) finding software and data structures suitable to handle and integrate large spatiotemporal data sets of RES potential and energy demand; and (5) the development of algorithms and tools to support the planning process of distributed energy systems that can take advantage of the high-resolution spatiotemporal data.

\section{Methodology}

In this section, a spatiotemporal modelling approach is presented, that integrates the models discussed and advances them in order to promote renewable energy generation planning at a municipal scale and fulfils the requirements enumerated in the previous section. Models to estimate RES potential and electricity demand and heating in high spatiotemporal resolution for municipalities as well as two alternative use paths for the generated data, in order to support the planning and decision making process, are proposed. The latter include a decision tree algorithm and a GIS-based user interface. The first serves to select electricity generation plants with the best match to electricity demand and to dimension necessary and optimal electricity storage systems. The second one provides an interactive environment for planning district heating networks, based on energy demand for heating of individual buildings and reductions on the demand (due to retrofitting measures), and the adoption of active solar energy harvesting systems.

The proposed methodology is graphically summarized in Fig. 4; it is described in the next subsections, and its multiple components are explained in detail together with case studies in [183-186]. The different parts of the methodology and the planning tools were implemented using the in-memory array processing environment of Python [187] and Numpy [188], the packages Scipy [189] and Pandas [190], and open source GIS tools including gdal/ogr [191], GRASS GIS [192] and QGIS [193]. TGRASS [157], the spatiotemporal database of GRASS GIS, was used for data management.

\section{Energy generation potential of fluctuating RES in high spatiotemporal resolution}

Three subsequent steps are proposed to calculate the potential of fluctuating RES in high spatiotemporal resolution. The first step is the use of a GIS-based procedure to reduce the study area only to the locations where RES-based energy generation plants could possibly be placed. In the case of solar active technologies (PV and $\mathrm{ST}$ ), rooftops represent the best possible locations since there is no conflict with other uses or resources. However, it is not technically possible to make use of the whole surface of the roof for PV (at least with most widely used PV technologies) or ST systems. Therefore, objects such as dormers and chimneys have to be excluded from the analysis. The remaining surface areas of a roof are classified based on the two main construction factors that influence the output of active solar systems, inclination (slope) and orientation (aspect) [194]. To produce this selection and classification, high-resolution DSM and building footprints are employed. The accuracy of the identification of every potential surface strongly depends on the quality and resolution of the spatial data. An example for the rooftop parts of three buildings classified in eight different aspects is presented in Fig. 5. As discussed in detail in [195], a DSM resolution of $25 \mathrm{~cm}$ (DSM0.25 in Fig. 5) is the best compromise between accuracy and amount of data to identify and classify suitable surfaces for active solar systems based merely on aspect and slope.

In the case of the selection of areas for wind power deployment, the procedure is not as straightforward as for solar technologies. A GIS-based procedure that excludes unsuitable areas due to legal and environmental factors is utilized. Since the municipality that is used for most of the case studies is located in Bavaria (Germany), the implemented restrictions correspond to the design and approval recommendations of wind turbines in Bavaria, as it is described in [196]. These exclude:

(a) Locations in a radius of $100 \mathrm{~m}$ from federal motorways, railways, power lines and federal, state and country roads;

(b) Locations in a radius of $500 \mathrm{~m}$ from air traffic areas, industrial buildings, national parks, landscape conservation areas, bird protection areas, biotopes and flora and fauna habitats;

(c) Areas in a radius of $800 \mathrm{~m}$ from residential buildings and buildings on mixed residential and commercial areas,

from wind power use. These types of restrictions can nonetheless be adapted to the local regulation of any particular study area globally.

The second step to calculate the potential of fluctuating RES in high spatiotemporal resolution consists of generating the time series of solar irradiance or available wind resources for every potential location identified in the previous step. These time series correspond to either a particular year or to a typical meteorological year. Solar irradiance is calculated in hourly or intra-hourly temporal resolution for every pixel inside of the suitable areas using the modules r.horizon and r.sun of GRASS GIS. r.sun is an open-source tool that has been widely used in merely spatial studies concerning active solar technologies, and it is a more flexible, efficient and reliable tool to calculate solar irradiance in high spatiotemporal resolution for entire municipalities than its 


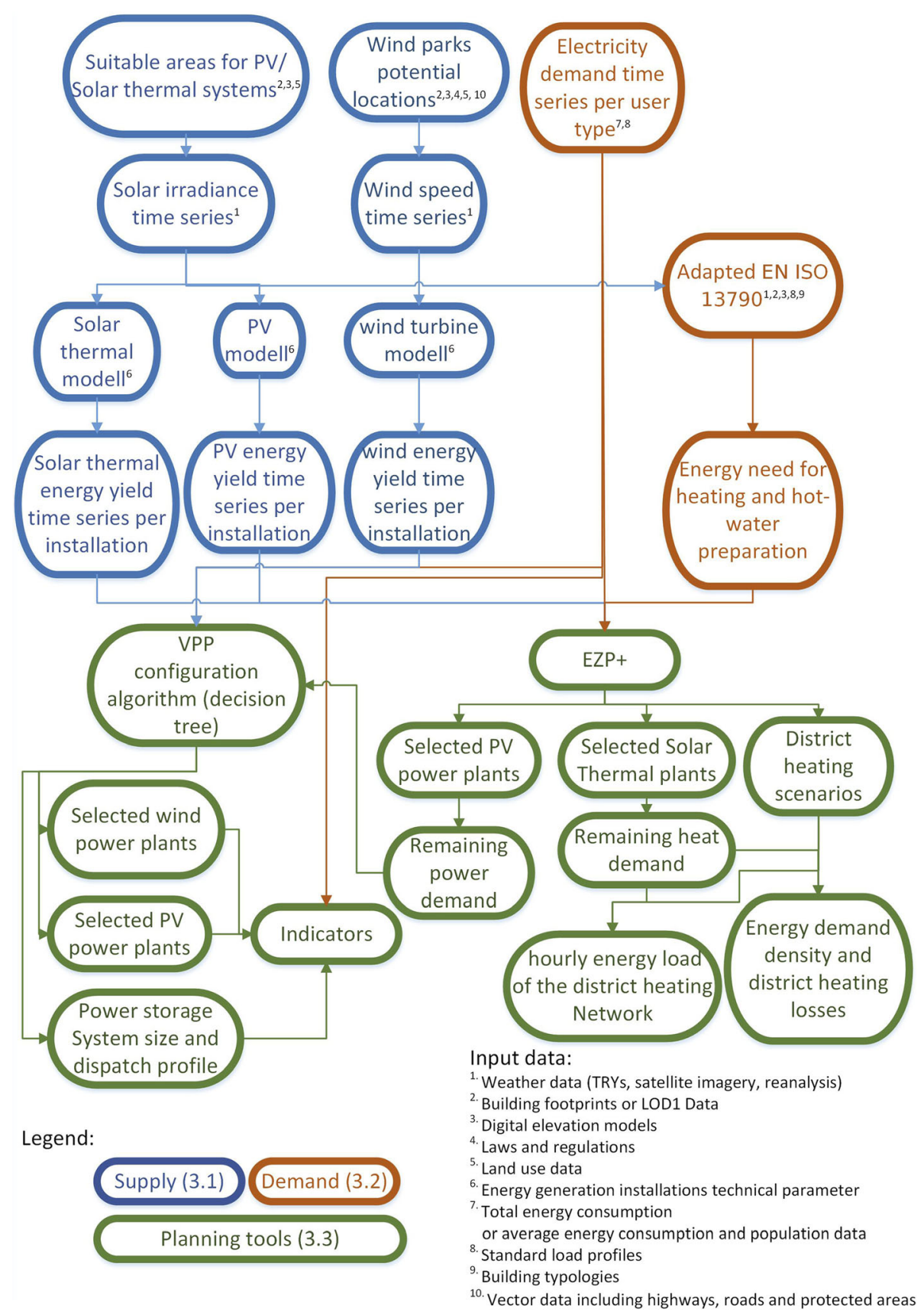

Fig. 4 Methodology overview: overall workflow of the proposed methodology

proprietary counterpart, solar analyst of ArcGIS [197]. Shadowing on the surfaces is taken into account by calculating the horizons due to near and distant objects, which are computed separately using r.horizon. The horizons of near objects such as neighbouring buildings, chimneys or dormers are calculated with a DSM with the highest available resolution. Horizons due to distant objects, such as mountains, in a radius of $230 \mathrm{~km}^{2}$ are calculated using a DSM of coarser resolution. Further atmospheric parameters (e.g. Linke turbidity factor) for the clear-sky calculation are retrieved from data sources with global coverage such as the SODA database [198]. The required data for estimating solar irradiance under real-sky conditions are acquired either from individual ground measurements, test reference years, satellite imagery-derived data or reanalysis data. Ground measurements and test reference years are the most accurate data sources, but satellite imagery-derived data and reanalysis data have better coverage and are suitable data sources for locations with a low density of ground 

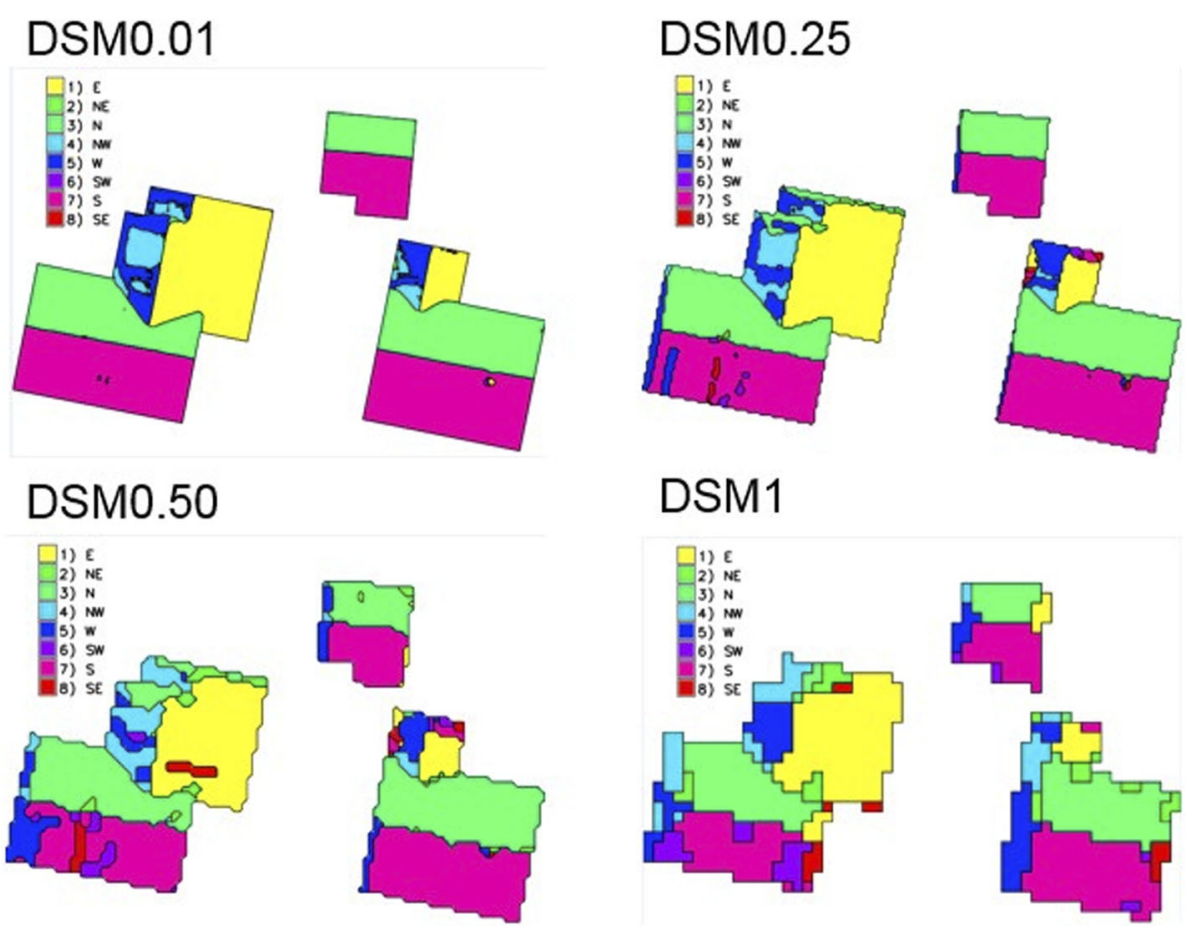

Fig. 5 DSM resolutions for rooftop surface identification: results of rooftop surface identification and classification for DSMs with resolutions ranging from $1 \mathrm{~cm} \times \mathrm{cm}$ (DSM0.01) to $1 \mathrm{~m} \times 1 \mathrm{~m}$ (DSM1). The LiDAR data to generate the DSM1 was provided by the Bavarian Surveying Agency (2014), http://geodaten.bayern.de. The data and methodology for generating the rest of the DSM corresponds to the one presented in [195]

stations [199]. Finally, the resulting real-sky irradiance data of all pixels in a certain surface is summarized in one single value. By doing this, time series of 1 year with a resolution of at least $1 \mathrm{~h}$ of solar irradiance for every suitable surface are generated.

For the case of wind resources, wind speed time series for every suitable area for wind turbines are calculated using the power law of logarithmic profiles for estimating wind speed at hub height. This requires certain wind speed reference data (ground measurements or reanalysis data) and information about the surface roughness length that can be estimated from land use data. The results are hourly or intra-hourly wind speed time series at hub height for every suitable area for wind turbines.

The third step is the calculation of the energy yield of every possible RE installation. The PV output is calculated based on the irradiance time series computed in the previous step, photovoltaic panel efficiency, a temperature correction factor, ambient air temperature, a reduction factor due to installation type, nominal operating temperature and the available surface area. In the case of ST systems, the relevant parameters are also the irradiance time series, ambient air temperature, the operational temperature of the system, the efficiency and the available surface area. Ambient temperature can be retrieved from test reference years or reanalysis data. For wind turbines, the power output is estimated using a turbine performance curve that depends on the capacity factor, cut-in wind speed, rated wind speed, cut-out wind speed, diameter of the rotor, rated power output and air mass density. The instantaneous output of the systems is assumed to remain constant during every time step (this implies that irradiance, temperature and wind speed remain unchanged during the considered time step length), and the final output are the energy generation time series of the respective installations.

\section{Energy demand for electricity, heating and water heating in high spatiotemporal resolution}

A widely used approach, identified in the literature review, is adopted to generate electricity demand time series: Yearly totals of electricity demand of the municipality from local grid operators are transformed to time series using the standardized load profiles provided by the German Federal Association of Energy and Water Management (BDEW- Bundesverband der Energie- und Wasserwirtschaft). These load profiles consider both daily and seasonal variations and are available in 15-min time steps for 11 different types of users. The underlying assumptions are that the actual demands tend to be similar to the standardized load profiles with an increased number of users (deviations around $\pm 10 \%$ ) [200] and that all users are part of the same grid. In the case where only residential users are studied, population data can also be used to calculate yearly electricity 
consumption, which can be transformed into time series using the standardized load profiles.

An UBEM approach is used to estimate the energy demand for heating and water heating. The methodology proposed in [179] is extended to consider location-dependent solar energy gains, which are calculated with the solar irradiance time series computed with the procedure described in the previous section. The core of this UBEM approach is a customized version of the simple hourly calculation procedure of the EN ISO 13790. The customization includes the consideration of only one building zone and the reduction of the input data to information about building quality provided by the database of the TABULA project. This thermal model is employed for each main building in a study area (secondary buildings such as stables, garages or tool deposits are omitted under the assumption that these are unheated buildings). Buildings are classified using georeferenced vector data of the buildings (LOD1) that include type of use, year of construction, number of storeys and the reference area (calculated from the building footprint and the number of storeys). Residential buildings are classified into the typologies of the TABULA project while non-residential buildings are arranged merely by the construction year class. Next, the customized version of the simple hourly calculation procedure of the EN ISO 13790 is employed for every building. The building construction quality data (e.g. $u$-values of walls and windows) are retrieved either from the particular building typology or from an average building representing a certain year class. The solar radiation gains are estimated with the same irradiance data used for the PV and ST systems. Since the underlying DSM has $2.5 \mathrm{D}$ and not 3D resolution and the r.sun tool also works only in $2.5 \mathrm{D}$, assumptions are necessary for the calculation of irradiance on vertical surfaces. The georeferenced data is used to omit walls that are covered by other buildings or objects from the calculation and to construct a buffer of $1 \mathrm{~m}$ outside of the walls that are actually hit by solar radiation. The average irradiance on these surfaces is adopted as input for the calculation of solar energy gains coming through each wall. Energy need for hot water preparation is calculated depending on the amount of hot water consumed in a certain time step (depending on the number of active occupants in a building and their total standard daily need of hot water) and a simple thermodynamic equation for determining the amount of energy necessary to heat the amount of water to the desired temperature in a certain time step. Additionally, compared to [179], the occupation model is not based on a stochastic model that relies on time of use surveys such as the one described in [201] but on a deterministic distribution of the number of occupants per dwelling, which depends on the electricity demand profile. This implies that heat gains due to occupation, appliances and lighting are correlated to the predicted electricity demand. The output of the UBEM is the time series of energy need for heating and hot water preparation for every building in a temporal resolution of $1 \mathrm{~h}$.

\section{Distributed renewable energy systems planning}

The challenge after producing the massive amount of high-resolution spatiotemporal RE potential and energy demand data is to make it usable for the planning and decision making processes. In order to accomplish this, two analysis alternatives are proposed. These are briefly described in the next sub-sections and explained in detail in [183] and [184].

\section{Sizing distributed renewable energy systems}

A decision tree to find the best match between the electricity generation profiles of multiple RES installations and the electricity demand of a municipality (or a part of it) is proposed. The core of the decision tree is a criterion called ProperF (Eq. 1) that rates the power output of every plant based on the amount of properly supplied energy (Eq. 2) and the amount of excess energy (Eq. 3.).

$$
\begin{aligned}
& \text { ProperF }=\left\{\begin{array}{l}
\frac{\sum_{t=1}^{T} \operatorname{PrS} u_{t}}{\sum_{t=1}^{T} \operatorname{Exc}_{t}} \text { if }\left(\mathrm{Exc}_{t}>0\right) \\
\sum_{t=1}^{T} \operatorname{PrSu}_{t} \text { if }\left(\mathrm{Exc}_{t}=0\right)
\end{array}\right. \\
& \operatorname{PrSu}_{t}=\left\{\begin{array}{l}
D_{t} \text { if }\left(E_{t} \geq D_{t}\right) \\
E_{t} \text { if }\left(E_{t}<D_{t}\right)
\end{array}\right. \\
& \operatorname{Exc}_{t}=\left\{\begin{array}{cc}
E_{t}-D_{t} \text { if }\left(E_{t}>D_{t}\right) \\
0 & \text { if }\left(E_{t} \leq D_{t}\right)
\end{array}\right.
\end{aligned}
$$

where $\mathrm{Exc}_{t}=$ amount of excess energy in the time step $t$ $D_{t}=$ local electricity demand at the time step $t$

$E_{t}=$ energy output of the power plant (wind or PV) in the time step $t$

$\mathrm{PrSu}_{t}=$ amount of proper supplied demand in the time step $t$

The decision tree starts by rating each potential RE installation against the local demand using ProperF. The RE power plant with the highest ProperF is selected, and its time series of electricity output is subtracted from the local demand load. Subsequently, the remaining RE power plants are rated again using the residual demand. A second RE power installation is selected based on ProperF. This selection process continues until the sum of the energy output of the RE energy generation plants equals a desired RES penetration rate. The final yield of the set of selected plants serves to dimension and calculate the state of charge of storage systems with sizes that are defined a 
priori, optimized to be used as much as possible or to store all produced electricity generated by the set of selected plants. By setting the storage capacity to a certain predefined value, the impact of the adoption of storage systems on the local energy matrix can be examined.

The contribution of the virtual power plant (constituted by the set of RE generation plants) to the local energy balance is assessed with a set of indicators. These include the total installed capacity (in $\mathrm{kW}$ ), variability of the output (in $\mathrm{kW}$ ), total unfulfilled demand (in MWh), total excess energy (in MWh), total properly supplied energy (in MWh), loss of power supply probability (LPSP), hours of supply higher than the highest demand, hours of supply higher than 1.5 times the highest demand, required storage energy capacity (in $\mathrm{MWh}$ ) and required dispatch power of the storage system (in $\mathrm{kW}$ ). A detailed mathematical description of these indicators is presented in [183]. The results of the indicators serve to evaluate the suitability of a certain RES target and the relevance of specific technologies for the local energy matrix and to define a road map of which installations should be actually build to achieve the desired objectives.

\section{A GIS-based user interface for planning district heating networks}

The evaluation of the viability of district heating systems is one of the topics that traditionally have been approached using GIS tools. These tools serve to evaluate, e.g. the energy demand density per meter of installed heating network, which is a decisive parameter for the construction or extension of the heating networks [140]. Usually, scenarios are constructed assuming certain level of refurbishment for the existent building stock. These are useful to predict to what extent district heating is viable if buildings are refurbished. However, using the time series of potential active solar energy installations and the energy demand data, it is possible to improve the analysis. A plug-in for the open-source QGIS software is implemented to extend the functionality of EZP, a tool for planning district heating networks that originally operated with data in yearly resolution [140]. With the new tool, it becomes possible to study the impact of the adoption of ST systems in the viability of a district heating network, to calculate a detailed dispatch profile for the heat generation plant and to calculate the exploitation potential of the remaining roof areas for PV as well as their contribution to cover the local electricity demand [180].

The plug-in, called EZP+, requires the spatiotemporal solar irradiance, the heat energy demand data, the potential roof areas suitable for PV and ST deployment in every building and the spatial data that was necessary to run the original EZP as input. The latter include georeferenced vector data with parcels and building footprints as well as the shape of the potential district heating network divided into a main network (constructed from sections that correspond to street names), and the network links to the buildings. Furthermore, the possible energy losses of the network and the PV/ST energy yields are not pre-calculated allowing the user to set several parameters to the particular conditions of the study area. If it is available, the user can provide specific data about the average yearly electricity demand of households, energy demand profiles of non-residential buildings, energy losses of the district heating network and the PV/ST technical parameters as well as the maximum desired PV/ST installation size per household. The last parameter serves to consider, e.g. local economic promotion mechanisms for certain PV/ST system sizes.

After providing the input data and parameters, the user selects the buildings that should be equipped with PV and ST systems. The yield calculations of the respective systems are performed on the fly for every selected building. To determine the PV potential of every building, the part of the roof with the highest solar radiation per year is selected. If the area of this roof part is not enough to accommodate a PV of the size defined by the plug-in user, further roof parts with the next highest solar radiation per year are also selected until the PV installation can be accommodated. The PV and ST installation size limit is the sum of the areas of all suitable roof parts. The area required by a PV installation is calculated based on the installed capacity and efficiency rate entered by the user. If there is more than one household in the building, the size of the PV installation for a certain building is multiplied by the number of households.

The ST potential of every building is calculated and presented analogically to the PV potential. ST plants are initially installed in the part of the roof that yields the highest solar irradiation. If a PV plant has been previously selected for the building, the available area of the roof is reduced. Similarly to the PV potential case, the energy output of the plants is compared in an hourly basis to the energy need for heating and/or warm water of the selected buildings (this is presented in the window "Solar Thermal" prompted by the plug-in. An example of it is presented in the window on the right side of Fig. 6). The comparison can be performed for one of three possible scenarios: current state of the building, building with basic refurbishment or building with advanced refurbishment. These different energy demand scenarios are pre-calculated in the energy need model for heating and hot water preparation with assumptions according to the data provided by the building typologies of the TABULA project [181]. Furthermore, the hourly energy need of the building is reduced by the output of the ST plant. The remaining energy need is the basis to calculate hourly load, total energy need and heat 


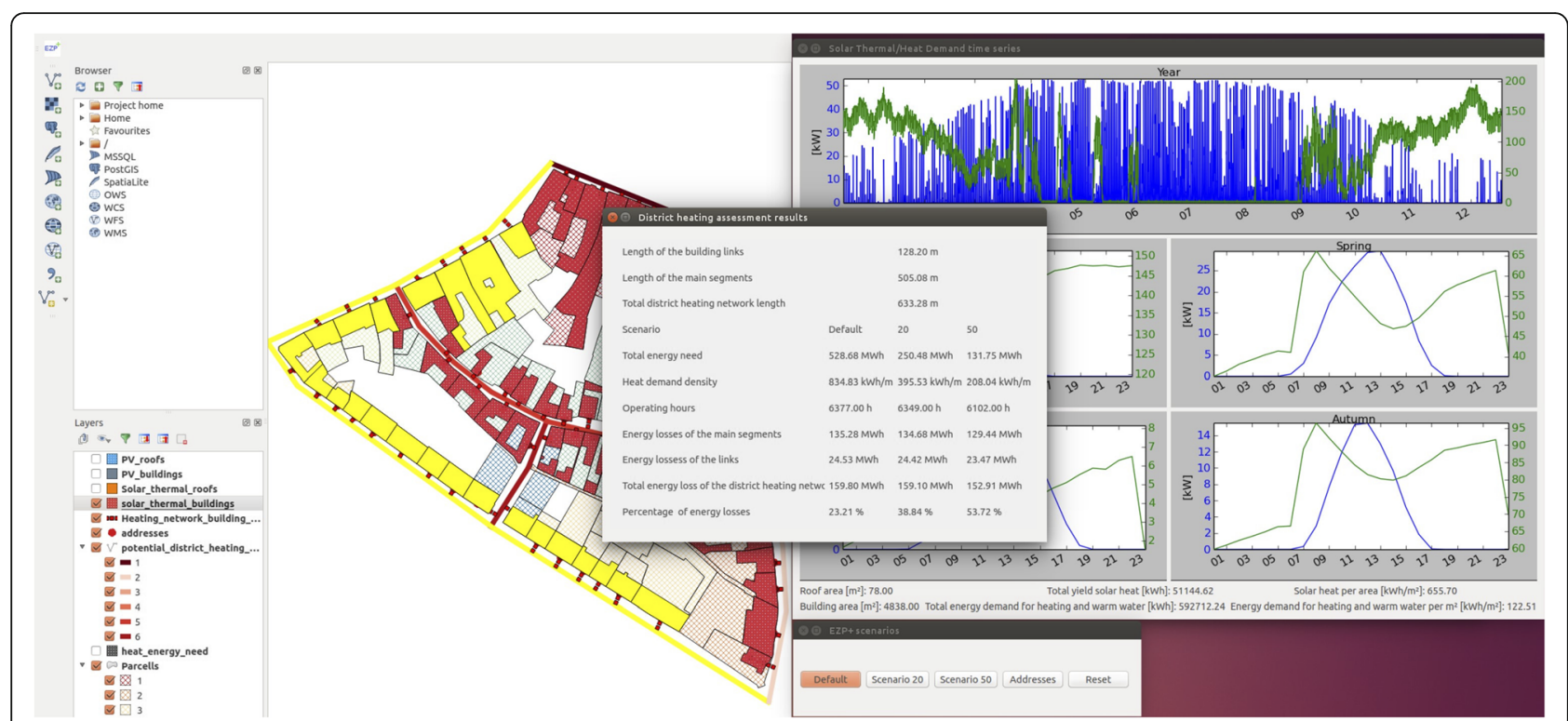

Fig. 6 EZP+ : Screenshot of the EZP+ QGIS plug-in: district heating assessment results in a demo location. The buildings with ST installations and the potential district heating network are highlighted in yellow [184]

demand density (factor between energy requirements and length of the network) for every building.

After all buildings, in which ST systems should be installed, have been selected, the feasibility of a district heating system is evaluated following the concept of EZP proposed in [140]. In the EZP, the municipality is pre-divided into sub-zones defined by street names, then a potential district heating network is drawn by following the course of the streets and connecting the centroid of every building to the main network. The sub-zones that are to be considered are selected interactively in a vector map as presented on the left side of Fig. 6 . The EZP+ plug-in calculates the length of the selected network and its corresponding links to the buildings. The remaining energy need profile (energy need of every building minus the output of the ST systems) of all buildings connected to the theoretical network is summed up on an hourly basis. This serves to calculate the amount of operation hours and the necessary energy output to cover the demand of the district heating network (in the EZP, the operational hours of the district heating network were provided a priori and the energy demand was distributed equally in every operation hour). Moreover, total yearly energy demand per building and the heat demand density are calculated. Heat losses are computed for the network segments and the network links to the buildings and for the system as a whole. All these results are summarized and presented on a window called "district heating assessment results", as can be seen in the centre of Fig. 6. Furthermore, the load profile of all selected sub-zones for the selected refurbishment scenario is stored as a csv file. The heat demand density is stored in the attribute table of a vector map for every group of buildings corresponding to a sub-zone. If the selection process of potential district heating networks is repeated for different parts of the municipality, it is possible to compare the heat demand density of alternative district heating networks. Planners can use the resulting map and the calculated indicators to evaluate the economic feasibility of potential district heating networks. In addition, the remaining electricity demand time series and the energy generation time series of the unused rooftop surfaces are also stored as a csv file. These data are a suitable input for the VPP configuration algorithm. A study of the electricity supply system that considers the decisions that have been made about the heat supply system can also be conducted.

\section{Results and discussion Case study results}

The components of the proposed methodology were applied in multiple case studies. The VPP configuration algorithm and the EZP+ were used with data from Waldthurn, a municipality in Germany, and Eggenburg, a municipality in Austria, respectively.

The data of Waldthurn, a rural municipality with 2019 inhabitants, 2,518 buildings and located in northeast Bavaria (Germany), were used to conduct multiple tests of the spatiotemporal models and the VPP configuration algorithm. In a first case study presented in detail in [183], the PV model is applied to the most populated area of the municipality $\left(4 \mathrm{~km}^{2}\right)$ and the electricity demand is estimated for the residential 438 buildings located there. The yearly energy generation potential is 
contrasted with the potential estimation in high temporal resolution, and different PV penetration rates are evaluated in detail. Main results include, e.g. that the best relations between all examined indicators are given for PV penetration levels below $40 \%$, and that a PV penetration around 20\% does not have major impacts on the local energy system. This analysis is extended in [185] to all types of users in the entire municipality $\left(30.1 \mathrm{~km}^{2}\right)$ and considers also the wind energy potential. The results of this case study showed that VPPs constituted by PV and wind power installations have better indicators than VPPs of PVs only. These results provide further evidence that there is a strong complementarity between solar and wind power, even in relatively small areas. The findings presented in $[202,203]$ about the advantages of combining wind and solar power to smooth the energy generation profiles were confirmed for the municipal scale. VPPs with similar amounts of wind and PV power installed capacity lead to better variability indicators, less storage requirements and better coverage of the demand. Moreover, it is shown that the methodology can be applied with modest computational requirements and serves to develop detailed deployment strategies of RES for municipalities.

Both case studies confirm the notable difference between the results that are obtained with a merely spatial analysis and the ones achieved with the spatiotemporal modelling approach. Following a merely spatial approach, the yearly PV energy generation potential is several times higher than the yearly electricity demand in both cases. In contrast, the spatiotemporal approach shows that the adoption of PV in a configuration, which is able to produce as much energy as the total yearly demand, would only cover the electricity demand in around $30 \%$ of the time steps. Such a PV-installed capacity would provide less than $50 \%$ of the electricity at the right moment and would create reverse loads with very high peaks during most parts of the summer in the absence of energy storage capacity. Alternatively, such a PV penetration would require massive amounts of storage capacity or curtailment. Even optimally sized storage systems reached a relation of $2 \mathrm{kWh}$ storage capacity per kilowattpeak PV installed capacity when the PV share increased to $60 \%$ of the yearly demand. It is only with penetration levels around $20 \%$ of the yearly demand that PV systems do not have major impacts on the local energy system. These results are comparable to the $20 \%$ PV penetration limit that can be achieved without producing reverse loads calculated by $[164,166,167]$. Furthermore, the best relations between all examined indicators were found for PV penetration levels below $40 \%$. In [173], similar results were presented. In this work, the authors developed a MILP to calculate the PV penetration rate that would minimize the energy provision costs and the maximum possible integration of PV for a village. For the case study of a Swiss village, these values were $25 \%$ and $65 \%$, respectively. The authors determined also that for the realization of the maximum PV penetration, at least $2 \mathrm{kWh}$ storage capacity per kilowattpeak installed PV would be required.

A further case study was conducted with the PV potential in high spatiotemporal resolution and the electricity demand of Waldthurn calculated in [185]. These data are used in [186] to evaluate the impact of small-scale storage systems on the PV penetration potential of the municipality. The adoption of a low share of storage systems improves indicators concerning energy utilization, variability and reliability of the energy supply. However, higher shares of storage systems only marginally improve these indicators.

Moreover, the use of the high-resolution spatiotemporal models illustrated that selecting PV installations based on the maximum yearly yield is not necessarily optimal and that traditional spatial and even state of the art spatiotemporal procedures (concerning relatively small geographic areas) overestimate the total PV potential in many cases. The case study presented in [183] indicates that a VPP configuration that includes PV installations with different "non-optimal" installation conditions (aspect, slope, shadowing), as the one obtained with ProperF, has a dispatch profile with less variability, requires less storage capacity, has a lower loss of power supply probability, produces less very high energy generation peaks and provides more energy when it is actually required. In addition, several studies assumed that "optimal" installation conditions are given for every surface suitable for PV deployment (see, e.g. [204] and [161]). However, the validity of this assumption could not be confirmed with the high resolution spatiotemporal analysis. The case study conducted to evaluate the impact of small-scale storage systems on the PV penetration potential shows that the assumption only holds for a reduced number of the potential surfaces. Differences between the energy yields of the PV rooftop plants with the highest energy production per year can easily be above $10 \%$ [186].

Data from Eggenburg, a municipality in Lower Austria, served to generate a trial data set to test all models and the EZP+. The case study presented in detail in [184] shows the effects of ST systems and building refurbishment on the energy demand density of a part of the municipality suitable for district heating. A relatively low share of ST adoption and standard refurbishment of the building stock can already transform a highly convenient and economic district heating network in a non-viable project. The integration of the proposed spatiotemporal models in the EZP+ serves to numerically determine key assumptions such as the operation hours of the district 
heating networks and the amount of energy that would be required in every time step. Furthermore, planners can use the tool to evaluate the impact of adopting refurbishment measurements and ST systems to the local heat energy demand.

\section{Strengths and weaknesses of the presented methodology} With the proposed methodology and the conducted case studies, it has been shown that GIS-based procedures for RES assessment and energy demand estimation can incorporate the temporal component using open-source software and modest computational capacities. Highresolution spatiotemporal models of energy demand and RES-based supply of municipalities can be developed, analysed and visualized with the hardware nowadays available in standard workstations. The core algorithms do not provide the most detailed output possible, but in exchange, these require relatively little input data and computational capacities. These characteristics make the algorithms suitable to be used to plan RES-based system for the entire municipalities. This has been shown by testing the proposed modelling approach with data sets that are considerably larger than the ones used in other state of the art studies. Instead of considering neighbourhoods or villages with a handful of buildings, a municipality with thousands of buildings has been studied under the proposed approach. Furthermore, an interactive tool such as the EZP+ is more understandable for general non-scientific users than optimization-driven methodologies and can easily reflect real intensions of the users for the construction of certain systems.

In terms of reproducibility, the methodology presents strengths in the proposed energy supply models and has an important drawback in the energy demand models. While spatiotemporal RES potential models can be used worldwide, energy demand models are difficult to use in the same form even between municipalities in neighbouring countries. On the one hand, developments in spatiotemporal data sets of temperature, solar radiation and wind speeds allow reproducing the proposed models in locations all around the globe. The main factor that should be considered carefully is the quality of the underlying reanalysis or satellite imagery-derived data sets. On the other hand, transferability and reproducibility of energy demand models are not as straightforward due to the dependency on the quality of local databases. For instance, if it would be of interest to apply the UBEMs presented in [168] or in [169] (case studies in Switzerland) for municipalities in neighbour countries such as Germany or Austria, considerably more detailed information of the building stock would be necessary than widely available. Unfortunately, the strategies for improving the underlying input data proposed in [141] (i.e. rapid site survey of the building façades, the compilation of already existing energy survey forms from individual buildings and full property surveys) are time consuming, expensive and do not necessarily solve the problem with the lack of data for non-residential buildings or the issues with data availability and data protection policies that hinder the studies.

Moreover, the proposed demand models and in general UBEMs are also strongly dependent on the behaviour of buildings' users. This is difficult to predict, and the available models rely mainly on specific local data. With the current state of widely available input data for energy demand models, it is difficult to expect that these present highly accurate results (even the building energy need estimation with high-quality input data presented in [180] for a location in Switzerland included buildings where errors higher than $50 \%$ were obtained) and that a worldwide application would be feasible in the near future. More general models such as the statistic raster-based models in [164] could be easier to replicate and use in other locations around the world, but these provide little information for the planning of individual energy generation installations. Data quality and availability are issues that should be addressed and that will considerably improve not only the reproducibility of the models but also the confidence on the derived results.

Finally, the information and results produced with the models can be easily visualized with (open source) GIS platforms. The results of the optimal sizing of a municipality-wide VPP can be presented in digital maps in an informative manner. The assessment and planning process of district heating networks can be interactively conducted using the EZP+ plug-in, in spite of the complexity and large size of the underlying data sets. Additionally, the implementation based on open-source GIS platforms and software allows the use of the proposed methodology and tools to a wider public than comparable approaches that rely on proprietary software such as proposed in [180]. This characteristic enables also other interested researchers to contribute to extend the current planning tools with further indicators and approaches beyond the current focus in technical characteristics of the systems. Future work can considerably profit from the implementation of the models in platforms designed for big data analysis such as the open-source raster array engine rasdaman [205] instead of classical GIS tools as well as from the migration from a workstation based to a cloud environment implementation.

\section{Strategic relevance of the presented methodology}

EZP+ is specifically designed to unfold strategic relevance for integrated spatial and energy planning. Yet, the case studies demonstrate the feasibility of the methods and show strengths and weaknesses of the proposed method, but are no role models for learning in planning processes. 
The strategic relevance of the presented methodology can be demonstrated on the case study Freistadt for the original EZP method in [206], which provided spatial modelling of biomass district heating supply options without temporal modelling: the planning method was applied during the revision of the municipal spatial development strategy and land use plan. First, it could be revealed that the town of Freistadt had many areas suitable for biomass district heating. Second, these results were shared with the house-owners of the respective areas and a question was asked if the houses would be connected immediately when a district heating grid would be built within 12 months. The yes-answers provided for an economically feasible grid, a utility provider was found and a biomass district heating system with integrated ST use was built and started operation about $1 \frac{1 / 2}{2}$ years after first research results were discussed with the local decision makers. Third, the municipal council introduced new regulations in spatial planning, zoning district heating supply areas taking potential energy savings via insulation of buildings as well as future urban developments into account, and introducing the regulation, that future development of residential, retail, office and public buildings should be built in these areas, so they can be developed as appropriately dense and mixed-function urban neighbourhoods (about the learning processes and their organisation, see [207]). This is especially important, as pure residential areas provide about $1.500-2.200$ full load hours, whereas 4.500 up to 6.000 full load hours can be assumed in mixed-function areas with residential, retail and office buildings as well as public facilities like schools, hospitals and indoor swimming pools [208].

$\mathrm{EZP}+$ is far more advanced, so a much higher relevance for strategic decision making can be expected. With spatiotemporal modelling of energy demand and renewable energy generation with different technologies, decision makers, planners and local communities are empowered to select networks of technological solutions as no-regret energy strategies on the local and regional level. The presented methodology can serve public dialogue in participatory planning processes in order to find the optimal solutions under current conditions without harming future development options. The strategic relevance also lays in the potential to make complex system interrelations visible and to provide the basis for the assessment of perceived impacts of potential goals and actions on the supply security and the necessary investments as well as their positive and negative environmental impacts. As EZP+ connects the spatial distribution of energy consumers with certain temporal consumer patterns with the spatial allocation of RES in the same spatial context, it can support decisions about two strategic dimensions: (1) in energy planning picking the best technological solution as a network of different technologies for securing energy supply at a given point including the dimensioning of energy generation, grid and storage, and (2) giving incentives for spatial planning to introduce and allocate land uses to places where they contribute to a resilient energy system by securing a favourable temporal pattern of energy demand in a certain spatial context. Therefore, EZP+ might be a powerful tool to provide the information base for climate change mitigation strategies. If climate change scenarios are used to estimate potential impacts of climate change on energy demand and renewable energy generation patterns, EZP+ might even be used for climate proofing of energy strategies.

\section{Conclusions}

Based on the results multiple conclusions can be drawn. Firstly, there is a vast difference between the results that are obtained from the merely spatial and the spatiotemporal models and analysis of variable RES potentials. It is likely that spatial-only analyses estimate very high RES potentials for a certain location, but only by knowing the distribution on time of the resource availability, it is possible to estimate which part of the potential can be actually used. The presented case studies illustrated that while the potential of variable RES based on yearly values was considerably larger than the energy demand, only a fraction of it can be deployed without compromising the quality and reliability of the local energy supply system. Independently of how many times higher the yearly generation potential from RES is compared to the yearly demand of a municipality, only RES penetration levels of around $20 \%$ of the yearly demand can be integrated into the local energy system without major impacts. Furthermore, RES penetration levels beyond $40 \%$ deteriorate the proposed supply quality and reliability indicators rapidly. Secondly, technological diversity is beneficial for the quality of a renewable energy supply. A VPP configured with PV installations selected based on the match of their energy yield to the demand (with different aspects and slopes) achieves better utilization, variability and reliability indicators than a VPP constituted by PV systems that maximize the energy yield. These indicators improve further if the VPPs include balanced combinations of wind and PV power plants and not only individual technologies. A VPP with similar installed capacities of PV and wind can increase the amount of energy delivered at the right moment by $20 \%$ and reduce the required energy storage to avoid curtailment by two thirds compared to, e.g. a PV-only VPP that would deliver the same total amount of energy per year. It is only by adopting combinations of the available technologies that the energy transition can be accomplished. Thirdly, spatiotemporal analysis tools serve to evaluate the relevance of specific technologies for the local energy matrix and to define a road map of which installations should actually be built to 
achieve the desired objectives. The implemented EZP+ plug-in makes use of state-of-the-art spatiotemporal models and an open-source platform to contribute to the development of integrated plans for building refurbishment, district heating networks and active solar energy generation systems in an interactive manner. Fourthly, input data quality and availability is improving, but there is still a long way to go until the spatiotemporal models presented here can be used for larger areas and for locations all around the world. The increasing amount and quality of spatiotemporal data sets for relevant parameters such as solar irradiance, temperature and wind speeds is important because it allows the reproducibility of the high-resolution spatiotemporal models in locations where ground measured data are scarce. However, high-quality input data for the determination of energy demand is limited and difficult to be accessed. It is important to invest some effort in the improvement of the quality, standardization and availability of the necessary databases.

Finally, it is important to note that the work presented in this paper is a contribution to the early stages of spatiotemporal modelling of distributed energy systems. This field of research has just recently started to emerge, and developments in key fields such as high-performance computing, big data analysis and Internet of Things will allow not only to improve the models and validate them, but also to create models of this level of detail for entire countries and continents. The better the models are, the more accurate strategic decision making in integrated spatial and energy planning can be supported by social learning processes of decision makers, planners and the public, so that governmental planning and bottom-up action can determine the path for a global energy transition to $100 \%$ renewables jointly and democratically.

\section{Abbreviations}

BREDEM: Building Research Establishment Domestic Energy Model; CEA: City Energy Analyst; CFSR: Climate Forecast System Reanalysis; CPU: Central processing unit; CSP: Concentrated solar power; DEM: Digital elevation model; DSM: Digital surface model; DOP: Digital orthophoto; DTM: Digital terrain model; ECMWF: European Centre for Medium-Range Weather Forecast; EHI: European Heating Index; EZP: Energy zones planning;

GIS: Geographic information systems; GPGPU: General purpose programming on graphic processing units; GPU: Graphic processing unit; IWU: Institut für Wohnen und Umwelt; KAMM: Karlsruhe Atmospheric Mesoscale Model; LiDAR: Light Detection and Ranging; LOD1: Vector data of buildings with level of detail 1; LPSP: Loss of power supply probability; MILP: Mixed-integer linear program; NCEP: National Centres for Environmental Prediction; NUTS: Nomenclature of territorial units for statistics; OBIA: Object-based image identification; PV: Photovoltaics; RES: Renewable energy sources; SEP: Solar energy planning; SHW: Solar hot water systems; TASES: Time and Space resolved Energy Simulation; TRNSYS: Transient System Simulation Tool; UBEM: Urban energy models; VPP: Virtual power plants; WRF: Weather Research and Forecasting model

\section{Acknowledgements}

We thank the Prof. Anton Kurir Foundation of BOKU University for the 2017 Doctoral Research Award.

\section{Funding}

This work was conducted as frameworks thesis of the doctoral project "Spatiatemporal modelling for renewable distributed energy generation planning for municipalities". The underlying research was mainly developed in the project "Spatial Energy Manager" funded by German Federal Ministry of Education and Research (grant number 03FH00712).

\section{Availability of data and materials}

The main data sources for the case studies were provided by local survey and meteorological agencies with the authorization of the corresponding municipalities. The authors do not have the permission to share or re-distribute these data.

\section{Authors' contributions}

Both authors contributed to the research design, results evaluation and elaboration of the manuscript. LRC developed the models and tools, conducted the case studies within his PhD study supervised by GS and prepared the first draft of the manuscript. GS enabled the acquisition of data for the Austrian case study, made available the code of the original Energiezonenplannung and added several sub-sections to the manuscript. Both authors revised, finalized and approved the manuscript.

\section{Authors' information}

Luis Ramirez Camargo is a researcher at the Institute for Applied Informatics of the Technische Hochschule Deggendorf (Germany) and lecturer at the Faculty of Electrical Engineering, Media Technology and Informatics of the same institution. He completed his doctoral thesis with honors at the Institute of Spatial Planning, Environmental Planning and Land Rearrangement at BOKU University under the supervision of Gernot Stoeglehner. His research interest include integrated spatial and energy planning, energy meteorology, renewable energies, spatiotemporal modelling and geographic information systems.

Gernot Stoeglehner is Professor for Spatial Planning and Research as well as Head of the Institute of Spatial Planning, Environmental Planning and Land Rearrangement at BOKU University. His research interests comprise integrated spatial and energy planning, sustainable spatial development, strategic spatial planning, environmental assessments and planning quality from the perspectives of planning theory and practice. The work comprises system analyses, the development of planning methods and planning tools and the provision and analysis of spatial data. Furthermore, GS is currently a coordinator of the BOKU energy cluster, a network of researchers and teachers active in energy research in order to facilitate a sustainable energy transition.

\section{Ethics approval and consent to participate}

Not applicable.

\section{Consent for publication}

Not applicable.

\section{Competing interests}

The authors declare that they have no competing interests.

\section{Publisher's Note}

Springer Nature remains neutral with regard to jurisdictional claims in published maps and institutional affiliations.

\section{Author details \\ 'Institute for Applied Informatics, Technologie Campus Freyung, Technische Hochschule Deggendorf, Grafenauer Str. 22, 94078 Freyung, Germany. ${ }^{2}$ Institute of Spatial Planning, Environmental Planning and Land Rearrangement, University of Natural Resources and Life Sciences Vienna, Peter-Jordan-Strasse 82, 1190 Vienna, Austria.}

Received: 19 June 2018 Accepted: 25 September 2018 Published online: 16 October 2018

\section{References}

1. United Nations. Paris agreement 2015. https://unfccc.int/sites/default/files/ english_paris_agreement.pdf. Accessed 4 Sept 2018. 
2. Borbely A-M, Kreider JF (2001) Distributed generation: the power paradigm for the new millennium. CRC Press, Boca Raton

3. Lopes JAP, Hatziargyriou N, Mutale J, Djapic P, Jenkins N (2007) Integrating distributed generation into electric power systems: a review of drivers, challenges and opportunities. Electr Power Syst Res 77:1189-1203. https:// doi.org/10.1016/j.epsr.2006.08.016

4. Asmus P (2010) Microgrids, virtual power plants and our distributed energy future. Electr J 23:72-82. https://doi.org/10.1016/.j.tej.2010.11.001

5. Bundesverband der Energie- und Wasserwirtschaft e.V. Erneuerbare Energien und das EEG (2015) Zahlen, Fakten, Grafiken (2015), Bundesverband der Energie- und Wasserwirtschaft e.V., Berlin

6. Bundesnetzagentur. Kraftwerksliste - Stand: 10.05.2016 2016. http://www bundesnetzagentur.de/DE/Sachgebiete/ElektrizitaetundGas/Unternehmen_ Institutionen/Nersorgungssicherheit/Erzeugungskapazitaeten/Kraftwerksliste/ kraftwerksliste-node.html. Accessed 24 June 2016.

7. Stoeglehner G, Narodoslawsky M (2009) How sustainable are biofuels? Answers and further questions arising from an ecological footprint perspective. Bioresour Technol 100:3825-3830. https://doi.org/10.1016/j.biortech.2009.01.059

8. Stoeglehner G, Neugebauer G, Erker S, Narodoslawsky M (2016) Integrated spatial and energy planning. Springer International Publishing, Cham

9. Burgess PJ, Rivas Casado M, Gavu J, Mead A, Cockerill T, Lord R et al (2012) A framework for reviewing the trade-offs between, renewable energy, food, feed and wood production at a local level. Renew Sustain Energy Rev 16: 129-142. https://doi.org/10.1016/j.rser.2011.07.142

10. Mendes G, loakimidis C, Ferrão P (2011) On the planning and analysis of Integrated Community Energy Systems: a review and survey of available tools. Renew Sustain Energy Rev 15:4836-4854. https://doi.org/10.1016/j.rser. 2011.07.067

11. Wolsink M (2012) The research agenda on social acceptance of distributed generation in smart grids: renewable as common pool resources. Renew Sustain Energy Rev 16:822-835. https://doi.org/10.1016/j.rser.2011.09.006

12. Angelis-Dimakis A, Biberacher M, Dominguez J, Fiorese G, Gadocha S, Gnansounou E et al (2011) Methods and tools to evaluate the availability of renewable energy sources. Renew Sustain Energy Rev 15:1182-1200. https:// doi.org/10.1016/j.rser.2010.09.049

13. Calvert K, Pearce JM, Mabee WE (2013) Toward renewable energy geoinformation infrastructures: applications of GIScience and remote sensing that build institutional capacity. Renew Sustain Energy Rev 18:416-429. https://doi.org/10.1016/j.rser.2012.10.024

14. Allegrini J, Orehounig K, Mavromatidis G, Ruesch F, Dorer V, Evins R (2015) A review of modelling approaches and tools for the simulation of districtscale energy systems. Renew Sustain Energy Rev 52:1391-1404. https://doi. org/10.1016/j.rser.2015.07.123

15. Holttinen $\mathrm{H}$, Meibom $\mathrm{P}$, Orths $\mathrm{A}$, van Hulle $\mathrm{F}$, Lange B, O'Malley M, et al (2006) Design and operation of power systems with large amounts of wind power. VTT Technical Research Centre of Finland, Helsinki

16. Paatero JV, Lund PD (2007) Effects of large-scale photovoltaic power integration on electricity distribution networks. Renew Energy 32:216-234. https://doi.org/10.1016/j.renene.2006.01.005

17. Passey R, Spooner T, MacGill I, Watt M, Syngellakis K (2011) The potential impacts of grid-connected distributed generation and how to address them: a review of technical and non-technical factors. Energy Policy 39: 6280-6290. https://doi.org/10.1016/j.enpol.2011.07.027

18. Solomon AA, Kammen DM, Callaway D (2014) The role of large-scale energy storage design and dispatch in the power grid: a study of very high grid penetration of variable renewable resources. Appl Energy 134:75-89. https:// doi.org/10.1016/j.apenergy.2014.07.095

19. Resch B, Sagl G, Törnros T, Bachmaier A, Eggers J-B, Herkel S et al (2014) GIS-based planning and modeling for renewable energy: challenges and future research avenues. ISPRS Int J Geo-Inf 3:662-692. https://doi.org/10. 3390/ijgi3020662

20. Fürst D, Scholles F (2001) Handbuch Theorien und Methoden der Raum- und Umweltplanung. Dortmund, Dortmunder Vertrieb für Bau- und Planungsliteratur

21. Scharpf F (2000) Interaktionsformen. In: Akteurszentrierter Institutionalismus in der Politikforschung. Leske \& Budrich, Opladen

22. Stoeglehner G, Narodoslawsky M (2008) Implementing ecological footprinting in decision-making processes. Land Use Policy 25:421-431. https://doi.org/10.1016/j.landusepol.2007.10.002

23. Erker S, Stangl R, Stoeglehner G (2017) Resilience in the light of energy crises - Part I: A framework to conceptualise regional energy resilience. J Clean Prod 164:420-433. https://doi.org/10.1016/j.jclepro.2017.06.163
24. Erker S, Stangl R, Stoeglehner G (2017) Resilience in the light of energy crises - Part II: Application of the regional energy resilience assessment. J Clean Prod 164:495-507. https://doi.org/10.1016/j.jclepro.2017.06.162

25. Milan C, Bojesen C, Nielsen MP (2012) A cost optimization model for 100\% renewable residential energy supply systems. Energy 48:118-127. https:// doi.org/10.1016/j.energy.2012.05.034

26. Yapa LS (1991) Is GIS appropriate technology? Int J Geogr Inf Syst 5:41-58. https://doi.org/10.1080/02693799108927830

27. Sørensen B, Meibom P (1999) GIS tools for renewable energy modelling. Renew Energy 16:1262-1267. https://doi.org/10.1016/S0960-1481(98)00514-X

28. Noon CE, Daly MJ (1996) GIS-based biomass resource assessment with BRAVO. Biomass Bioenergy 10:101-109. https://doi.org/10.1016/09619534(95)00065-8

29. Graham RL, Liu W, Downing M, Noon CE, Daly M, Moore A (1997) The effect of location and facility demand on the marginal cost of delivered wood chips from energy crops: a case study of the state of Tennessee. Biomass Bioenergy 13:117-123. https://doi.org/10.1016/S0961-9534(97)00022-6

30. Florin M, Gabriel E (1991) Integrated resource management: the answer to a socio-economic problem. GeoJournal 25:109-113. https://doi.org/10.1007/ BF00179777

31. Simmons D, Hill J (1995) Farming the winds: mapping renewable energy resources with GIS. GIS Eur 4:30-32

32. Biljecki F (2016) A scientometric analysis of selected GIScience journals. Int Geogr Inf Sci 30:1302-1335. https://doi.org/10.1080/13658816.2015.1130831

33. Ritter $P(1986)$ Computationally simple slope and aspect generation algorithm. American Society of Photogrammetry, Anchorage, pp 72-76

34. Martín AG, Cabello FP, de la Riva Fernández J, Puigdevall JP, Herranz EA (2005) Estimación de la biomasa residual forestal mediante técnicas de teledetección y SIG en masas puras de Pinus halepensis y P. sylvestris. Proc 4th Congr For Esp

35. Maselli F, Barbati A, Chiesi M, Chirici G, Corona P (2006) Use of remotely sensed and ancillary data for estimating forest gross primary productivity in Italy. Remote Sens Environ 100:563-575. https://doi.org/10.1016/.rse.2005.11.010

36. Labrecque S, Fournier RA, Luther JE, Piercey D (2006) A comparison of four methods to map biomass from Landsat-TM and inventory data in western Newfoundland. For Ecol Manag 226:129-144. https://doi.org/10.1016/j. foreco.2006.01.030

37. Bernetti I, Fagarazzi C, Fratini R (2004) A methodology to anaylse the potential development of biomass-energy sector: an application in Tuscany. For Policy Econ 6:415-432. https://doi.org/10.1016/j.forpol.2004.03.018

38. Zhao K, Popescu S, Nelson R (2009) Lidar remote sensing of forest biomass: a scale-invariant estimation approach using airborne lasers. Remote Sens Environ 113:182-196. https://doi.org/10.1016/j.rse.2008.09.009

39. Andújar D, Escolà A, Rosell-Polo JR, Sanz R, Rueda-Ayala V, FernándezQuintanilla C, et al. A LiDAR-based system to assess poplar biomass. Gesunde Pflanz 2016;68(3):155-162. https://doi.org/10.1007/s10343-0160369-1.

40. Ferraz A, Saatchi S, Mallet C, Meyer V (2016) Lidar detection of individual tree size in tropical forests. Remote Sens Environ 183:318-333. https://doi. org/10.1016/j.rse.2016.05.028

41. Ahamed T, Tian L, Zhang Y, Ting KC (2011) A review of remote sensing methods for biomass feedstock production. Biomass Bioenergy 35:24552469. https://doi.org/10.1016/j.biombioe.2011.02.028

42. Masera O, Ghilardi A, Drigo R, Angel Trossero M (2006) WISDOM: a GISbased supply demand mapping tool for woodfuel management. Biomass Bioenergy 30:618-637. https://doi.org/10.1016/j.biombioe.2006.01.006

43. Frombo F, Minciardi R, Robba M, Sacile R (2009) A decision support system for planning biomass-based energy production. Energy 34:362-369. https:// doi.org/10.1016/j.energy.2008.10.012

44. Kinoshita T, Inoue K, Iwao K, Kagemoto H, Yamagata Y (2009) A spatial evaluation of forest biomass usage using GIS. Appl Energy 86:1-8. https:// doi.org/10.1016/j.apenergy.2008.03.017

45. Tatsiopoulos I (2003) Economic aspects of the cotton-stalk biomass logistics and comparison of supply chain methods. Biomass Bioenergy 24:199-214. https://doi.org/10.1016/S0961-9534(02)00115-0

46. Zhan F, Chen X, Noon C, Wu G (2005) A GIS-enabled comparison of fixed and discriminatory pricing strategies for potential switchgrass-to-ethanol conversion facilities in Alabama. Biomass Bioenergy 28:295-306. https://doi. org/10.1016/j.biombioe.2004.06.006

47. Graham RL, English BC, Noon CE (2000) A geographic information system-based modeling system for evaluating the cost of delivered 
energy crop feedstock. Biomass Bioenergy 18:309-329. https://doi.org/ 10.1016/S0961-9534(99)00098-7

48. Van Meerbeek K, Ottoy S, De Meyer A, Van Schaeybroeck T, Van Orshoven J, Muys B et al (2015) The bioenergy potential of conservation areas and roadsides for biogas in an urbanized region. Appl Energy 154:742-751. https://doi.org/10.1016/j.apenergy.2015.05.007

49. Bojesen M, Skov-Petersen H, Gylling M (2015) Forecasting the potential of Danish biogas production - spatial representation of Markov chains. Biomass Bioenergy 81:462-472. https://doi.org/10.1016/j.biombioe.2015.07.030

50. Sliz-Szkliniarz B, Vogt J (2012) A GIS-based approach for evaluating the potential of biogas production from livestock manure and crops at a regional scale: a case study for the Kujawsko-Pomorskie Voivodeship. Renew Sustain Energy Rev 16:752-763. https://doi.org/10.1016/j.rser.2011.09.001

51. Schmidt J, Leduc S, Dotzauer E, Kindermann G, Schmid E (2010) Costeffective $\mathrm{CO} 2$ emission reduction through heat, power and biofuel production from woody biomass: a spatially explicit comparison of conversion technologies. Appl Energy 87:2128-2141. https://doi.org/10. 1016/j.apenergy.2009.11.007

52. Schmidt J, Leduc S, Dotzauer E, Kindermann G, Schmid E (2010) Potential of biomass-fired combined heat and power plants considering the spatial distribution of biomass supply and heat demand. Int J Energy Res 34:970985. https://doi.org/10.1002/er.1623

53. Höltinger S, Schmidt J, Schönhart M, Schmid E (2014) A spatially explicit techno-economic assessment of green biorefinery concepts. Biofuels Bioprod Biorefining 8:325-341. https://doi.org/10.1002/bbb.1461

54. Freppaz D, Minciardi R, Robba M, Rovatti M, Sacile R, Taramasso A (2004) Optimizing forest biomass exploitation for energy supply at a regional level. Biomass Bioenergy 26:15-25. https://doi.org/10.1016/50961-9534(03)00079-5

55. Alexander P, Moran D, Rounsevell MD, Smith P (2013) Modelling the perennial energy crop market: the role of spatial diffusion. J R Soc Interface R Soc 10:20130656

56. Inman RH, Pedro HTC, Coimbra CFM (2013) Solar forecasting methods for renewable energy integration. Prog Energy Combust Sci 39:535-576. https://doi.org/10.1016/j.pecs.2013.06.002

57. Šúri M, Huld TA, Dunlop ED (2005) PV-GIS: a web-based solar radiation database for the calculation of PV potential in Europe. Int J Sustain Energy 24:55-67. https://doi.org/10.1080/14786450512331329556

58. Arán Carrión J, Espín Estrella A, Aznar Dols F, Zamorano Toro M, Rodríguez M, Ramos Ridao A (2008) Environmental decision-support systems for evaluating the carrying capacity of land areas: optimal site selection for grid-connected photovoltaic power plants. Renew Sustain Energy Rev 12:2358-2380. https://doi.org/10.1016/j.rser.2007.06.011

59. Wiginton LK, Nguyen HT, Pearce JM (2010) Quantifying rooftop solar photovoltaic potential for regional renewable energy policy. Comput Environ Urban Syst 34:345-357. https://doi.org/10.1016/j.compenvurbsys.2010.01.001

60. Belmonte S (2009) Evaluación multicriterio para el uso alternativo de energías renovables en la Ordenación Territorial del Valle de Lerma. Tesis doctoral. Documento final y Cartografía digital. Doctorado en Ciencias Área Energías Renovables. Facultad de Ciencias Exactas. Universidad Nacional de Salta located in Salta Argentina

61. McIntyre JH (2012) Community-scale assessment of rooftop-mounted solar energy potential with meteorological, atlas, and GIS data: a case study of Guelph, Ontario (Canada). Energy Sustain Soc 2:23. https://doi.org/10.1186/ 2192-0567-2-23

62. Aydin NY, Kentel E, Duzgun S (2010) GIS-based environmental assessment of wind energy systems for spatial planning: a case study from Western Turkey. Renew Sustain Energy Rev 14:364-373. https://doi.org/10.1016/j.rser. 2009.07.023

63. Mari R, Bottai L, Busillo C, Calastrini F, Gozzini B, Gualtieri G (2011) A GIS-based interactive web decision support system for planning wind farms in Tuscany (Italy). Renew Energy 36:754-763. https://doi.org/10.1016/.renene.2010.07.005

64. Sliz-Szkliniarz B, Vogt J (2011) GIS-based approach for the evaluation of wind energy potential: a case study for the Kujawsko-Pomorskie Voivodeship. Renew Sustain Energy Rev 15:1696-1707. https://doi.org/10. 1016/j.rser.2010.11.045

65. van Haaren R, Fthenakis V (2011) GIS-based wind farm site selection using spatial multi-criteria analysis (SMCA): evaluating the case for New York State. Renew Sustain Energy Rev 15:3332-3340. https//doi.org/10.1016/j.rser.2011.04.010

66. Grassi S, Chokani N, Abhari RS (2012) Large scale technical and economical assessment of wind energy potential with a GIS tool: case study lowa. Energy Policy 45:73-85. https://doi.org/10.1016/j.enpol.2012.01.061
67. Janjai S, Masiri I, Promsen W, Pattarapanitchai S, Pankaew P, Laksanaboonsong J et al (2014) Evaluation of wind energy potential over Thailand by using an atmospheric mesoscale model and a GIS approach. J Wind Eng Ind Aerodyn 129:1-10. https://doi.org/10.1016/j.jweia.2014.03.010

68. Promsen W, Masiri I, Janjai S (2012) Development of microscale wind maps for Phaluay Island, Thailand. Procedia Eng 32:369-375. https://doi.org/10. 1016/j.proeng.2012.01.1281

69. Tsoutsos T, Tsitoura I, Kokologos D, Kalaitzakis K (2015) Sustainable siting process in large wind farms case study in Crete. Renew Energy 75:474-480. https://doi.org/10.1016/..renene.2014.10.020

70. Freitas S, Catita C, Redweik P, Brito MC (2015) Modelling solar potential in the urban environment: state-of-the-art review. Renew Sustain Energy Rev 41:915-931. https://doi.org/10.1016/j.rser.2014.08.060

71. Fu P, Rich PM. The solar analyst 1.0 user manual 2000. Helios Environmental Modeling Institute, Lawrence

72. Hofierka J, Suri M (2002) The solar radiation model for Open source GIS: implementation and applications. Proc. Open Source GIS-GRASS Users Conf. GIS-GRASS users conference, Trento, pp 1-19

73. Kanters J, Wall M, Kjellsson E (2014) The solar map as a knowledge base for solar energy use. Energy Procedia 48:1597-1606. https://doi.org/10.1016/j. egypro.2014.02.180

74. ESRI Deutschland GmbH. ArcGIS Help 10.1 - Area Solar Radiation (Spatial Analyst) 2013. http://resources.arcgis.com/de/help/main/10.1/index.html\#// 009z000000t5000000 (accessed 31 Jan 2014).

75. Šúri M, Hofierka J (2004) A new GIS-based solar radiation model and its application to photovoltaic assessments. Trans GIS 8:175-190. https://doi. org/10.1111/j.1467-9671.2004.00174.x

76. Ruiz-Arias JA, Tovar-Pescador J, Pozo-Vázquez D, Alsamamra H (2009) A comparative analysis of DEM-based models to estimate the solar radiation in mountainous terrain. Int J Geogr Inf Sci 23:1049-1076. https://doi.org/10. 1080/13658810802022806

77. Hofierka J, Kaňuk J (2009) Assessment of photovoltaic potential in urban areas using open-source solar radiation tools. Renew Energy 34:2206-2214. https://doi.org/10.1016/j.renene.2009.02.021

78. Martínez-Durbán M, Zarzalejo LF, Bosch JL, Rosiek S, Polo J, Batlles FJ (2009) Estimation of global daily irradiation in complex topography zones using digital elevation models and meteosat images: comparison of the results. Energy Convers Manag 50:2233-2238. https://doi.org/10.1016/j.enconman. 2009.05.009

79. Bosch JL, Batlles FJ, Zarzalejo LF, López G (2010) Solar resources estimation combining digital terrain models and satellite images techniques. Renew Energy 35:2853-2861. https://doi.org/10.1016/j.renene.2010.05.011

80. Ruiz-Arias JA, Cebecauer T, Tovar-Pescador J, Šúri M (2010) Spatial disaggregation of satellite-derived irradiance using a high-resolution digital elevation model. Sol Energy 84:1644-1657. https://doi.org/10.1016/.jsolener.2010.06.002

81. Haurant $P$, Muselli M, Pillot $B$, Oberti P (2012) Disaggregation of satellite derived irradiance maps: evaluation of the process and application to Corsica. Sol Energy 86:3168-3182. https://doi.org/10.1016/j.solener.2012.08.010

82. Ramirez Camargo L, Dorner W. Integrating satellite imagery-derived data and GIS-based solar radiation algorithms to map solar radiation in high temporal and spatial resolutions for the province of Salta, Argentina. vol. 10005, Edinburgh: SPIE Remote Sensing 2016, 100050E-11. https://doi.org/ 10.1117/12.2242042.

83. Šúri M, Huld TA, Dunlop ED, Ossenbrink HA (2007) Potential of solar electricity generation in the European Union member states and candidate countries. Sol Energy 81:1295-1305. https://doi.org/10.1016/j.solener.2006.12.007

84. Huld T, Amillo A (2015) Estimating PV module performance over large geographical regions: the role of irradiance, air temperature, wind speed and solar spectrum. Energies 8:5159-5181. https://doi.org/10.3390/en8065159

85. Gastli A, Charabi Y (2010) Solar electricity prospects in Oman using GISbased solar radiation maps. Renew Sustain Energy Rev 14:790-797. https:// doi.org/10.1016/j.rser.2009.08.018

86. Izquierdo S, Montañés C, Dopazo C, Fueyo N (2011) Roof-top solar energy potential under performance-based building energy codes: the case of Spain. Sol Energy 85:208-213. https://doi.org/10.1016/j.solener.2010.11.003

87. Izquierdo S, Rodrigues M, Fueyo N (2008) A method for estimating the geographical distribution of the available roof surface area for large-scale photovoltaic energy-potential evaluations. Sol Energy 82:929-939. https:// doi.org/10.1016/j.solener.2008.03.007

88. Rumbayan M, Abudureyimu A, Nagasaka K (2012) Mapping of solar energy potential in Indonesia using artificial neural network and geographical 
information system. Renew Sustain Energy Rev 16:1437-1449. https://doi. org/10.1016/j.rser.2011.11.024

89. Righini R, Grossi Gallegos H, Raichijk C (2005) Approach to drawing new global solar irradiation contour maps for Argentina. Renew Energy 30:12411255. https://doi.org/10.1016/j.renene.2004.10.010

90. Geofísica, Facultad de Ciencias Físicas y Matemáticas Universidad de Chile (2016) Explorador Solar Chile - Manual de Usuario Versión 2016. Facultad de Ciencias Físicas y Matemáticas Universidad de Chile, Santiago de Chile

91. Bergamasco L, Asinari P (2011) Scalable methodology for the photovoltaic solar energy potential assessment based on available roof surface area: further improvements by ortho-image analysis and application to Turin (Italy). Sol Energy 85:2741-2756. https://doi.org/10.1016/j.solener.2011.08.010

92. Bergamasco L, Asinari P (2011) Scalable methodology for the photovoltaic solar energy potential assessment based on available roof surface area: application to Piedmont Region (Italy). Sol Energy 85:1041-1055. https://doi. org/10.1016/j.solener.2011.02.022

93. Schallenberg-Rodríguez J (2013) Photovoltaic techno-economical potential on roofs in regions and islands: the case of the Canary Islands. Methodological review and methodology proposal. Renew Sustain Energy Rev 20:219-239. https://doi.org/10.1016/j.rser.2012.11.078

94. Sánchez-Lozano JM, Teruel-Solano J, Soto-Elvira PL, Socorro García-Cascales M (2013) Geographical Information Systems (GIS) and Multi-Criteria Decision Making (MCDM) methods for the evaluation of solar farms locations: case study in south-eastern Spain. Renew Sustain Energy Rev 24:544-556. https:// doi.org/10.1016/j.rser.2013.03.019

95. Nguyen HT, Pearce JM (2010) Automated quantification of solar photovoltaic potential in cities. Int Rev Spat Plan Sustain Dev 1:57-70

96. Jo JH, Otanicar TP (2011) A hierarchical methodology for the mesoscale assessment of building integrated roof solar energy systems. Renew Energy 36:2992-3000. https://doi.org/10.1016/.j.renene.2011.03.038

97. Kryza M, Szymanowski M, Migała K, Pietras M (2010) Spatial information on total solar radiation: application and evaluation of the r.sun model for the Wedel Jarlsberg Land, Svalbard. Pol Polar Res 31:17-32. https://doi.org/10. 4202/ppres.2010.02

98. Sun Y, Hof A, Wang R, Liu J, Lin Y, Yang D (2013) GIS-based approach for potential analysis of solar PV generation at the regional scale: a case study of Fujian Province. Energy Policy 58:248-259. https://doi.org/10.1016/j.enpol. 2013.03.002

99. Ludwig D, Klärle M, Lanig S (2008) Automatisierte Standortanalyse für die Solarnutzung auf Dachflächen über hochaufgelöste Laserscanningdaten. Angew Geoinformatik 20:466-475

100. Kodysh JB, Omitaomu OA, Bhaduri BL, Neish BS (2013) Methodology for estimating solar potential on multiple building rooftops for photovoltaic systems. Sustain Cities Soc 8:31-41. https://doi.org/10.1016/j.scs.2013.01.002

101. La Gennusa M, Lascari G, Rizzo G, Scaccianoce G, Sorrentino G (2011) A model for predicting the potential diffusion of solar energy systems in complex urban environments. Energy Policy 39:5335-5343. https://doi.org/ 10.1016/j.enpol.2011.05.031

102. Brito MC, Gomes N, Santos T, Tenedório JA (2012) Photovoltaic potential in a Lisbon suburb using LiDAR data. Sol Energy 86:283-288. https://doi.org/ 10.1016/j.solener.2011.09.031

103. Nguyen HT, Pearce JM (2012) Incorporating shading losses in solar photovoltaic potential assessment at the municipal scale. Sol Energy 86: 1245-1260. https://doi.org/10.1016/j.solener.2012.01.017

104. Agugiaro G, Nex F, De Remondino F, Filippi R, Droghetti S, Furlanello C (2012) Solar radiation estimation on building roofs and web-based solar cadaster. ISPRS Ann Photogramm Remote Sens Spat Inf Sci 1:177-182

105. Lukač N, Žalik B (2013) GPU-based roofs' solar potential estimation using LiDAR data. Comput Geosci 52:34-41. https://doi.org/10.1016/j. cageo.2012.10.010

106. Lukač N, Žlaus D, Seme S, Žalik B, Štumberger G (2013) Rating of roofs' surfaces regarding their solar potential and suitability for PV systems, based on LiDAR data. Appl Energy 102:803-812. https://doi.org/10.1016/j.apenergy. 2012.08.042

107. Lukač N, Seme S, Žlaus D, Štumberger G, Žalik B (2014) Buildings roofs photovoltaic potential assessment based on LiDAR (Light Detection And Ranging) data. Energy 66:598-609. https://doi.org/10.1016/j.energy.2013.12.066

108. Huang Y, Chen Z, Wu B, Chen L, Mao W, Zhao F et al (2015) Estimating roof solar energy potential in the downtown area using a GPU-accelerated solar radiation model and airborne LiDAR data. Remote Sens 7:17212-17233. https://doi.org/10.3390/rs71215877
109. Redweik P, Catita C, Brito M (2013) Solar energy potential on roofs and facades in an urban landscape. Sol Energy 97:332-341. https://doi.org/10. 1016/j.solener.2013.08.036

110. Catita C, Redweik P, Pereira J, Brito MC (2014) Extending solar potential analysis in buildings to vertical facades. Comput Geosci 66:1-12. https://doi. org/10.1016/j.cageo.2014.01.002

111. Jakubiec JA, Reinhart CF (2013) A method for predicting city-wide electricity gains from photovoltaic panels based on LiDAR and GIS data combined with hourly Daysim simulations. Sol Energy 93:127-143. https://doi.org/10. 1016/j.solener.2013.03.022

112. Genossenschaft Meteotest (2016) Windpotentialanalyse für Windatlas.ch: Jahresmittelwert der modellierten Windgeschwindigkeit und Windrichtung. Bundesamt für Energie. EnergieSchweiz, Ittingen

113. Hoogwijk M, de Vries B, Turkenburg W (2004) Assessment of the global and regional geographical, technical and economic potential of onshore wind energy. Energy Econ 26:889-919. https://doi.org/10.1016/j.eneco.2004.04.016

114. New M, Hulme M, Jones P (1999) Representing twentieth-century spacetime climate variability. Part I: Development of a 1961-90 mean monthly terrestrial climatology. J Clim 12:829-856

115. Himri Y, Rehman S, Draoui B, Himri S (2008) Wind power potential assessment for three locations in Algeria. Renew Sustain Energy Rev 12: 2495-2504. https://doi.org/10.1016/j.rser.2007.06.007

116. Hawkins SL (2012) High resolution reanalysis of wind speeds over the British Isles for wind energy integration. The University of Edinburgh, Edinburgh

117. Krenn A, Winkelmeier J, Tiefgraber C, René Cattin G, Müller S, Truhetz H, et al (2011) Windatlas und Windpotentialstudie Österreich (Endbericht). Klimaund Energiefonds des Bundes, Vienna

118. Bayerisches Staatsministerium für Wirtschaft und Medien, Energie und Technologie (2014) Bayerischer Windatlas. Bayerisches Staatsministerium für Wirtschaft und Medien, Energie und Technologie, Munich

119. Uppala SM, KÅllberg PW, Simmons AJ, Andrae U, Bechtold VDC, Fiorino M et al (2005) The ERA-40 re-analysis. Q J R Meteorol Soc 131:2961-3012. https://doi.org/10.1256/qj.04.176

120. Personn, Anders. ERA-Interim dataset (January 1979 to present) 2015. European Centre for Medium-Range Weather Forecasts, Reading

121. Saha S, Moorthi S, Pan H-L, Wu X, Wang J, Nadiga S et al (2010) The NCEP climate forecast system reanalysis. Bull Am Meteorol Soc 91:1015-1057. https://doi.org/10.1175/2010BAMS3001.1

122. Swan LG, Ugursal VI (2009) Modeling of end-use energy consumption in the residential sector: a review of modeling techniques. Renew Sustain Energy Rev 13:1819-1835. https://doi.org/10.1016/j.rser.2008.09.033

123. Kavgic M, Mavrogianni A, Mumovic D, Summerfield A, Stevanovic Z, Djurovic-Petrovic M (2010) A review of bottom-up building stock models for energy consumption in the residential sector. Build Environ 45:16831697. https://doi.org/10.1016/j.buildenv.2010.01.021

124. Reinhart CF, Cerezo Davila C (2016) Urban building energy modeling - a review of a nascent field. Build Environ 97:196-202. https://doi.org/10.1016/j. buildenv.2015.12.001

125. Voivontas D, Tsiligiridis G, Assimacopoulos D (1998) Solar potential for water heating explored by GIS. Sol Energy 62:419-427. https://doi.org/10.1016/ S0038-092X(98)00027-9

126. Möller B, Lund H (2010) Conversion of individual natural gas to district heating: geographical studies of supply costs and consequences for the Danish energy system. Appl Energy 87:1846-1857. https://doi.org/10.1016/j. apenergy.2009.12.001

127. Petrovic S, Karlsson K (2014) Model for determining geographical distribution of heat saving potentials in Danish building stock. ISPRS Int J Geo-Inf 3:143-165. https://doi.org/10.3390/ijgi3010143

128. Gils HC, Cofala J, Wagner F, Schöpp W (2013) GIS-based assessment of the district heating potential in the USA. Energy 58:318-329. https://doi.org/10. 1016/j.energy.2013.06.028

129. Connolly D, Lund H, Mathiesen BV, Werner S, Möller B, Persson U et al (2014) Heat Roadmap Europe: combining district heating with heat savings to decarbonise the EU energy system. Energy Policy 65:475-489. https://doi. org/10.1016/j.enpol.2013.10.035

130. Kaijuka E (2007) GIS and rural electricity planning in Uganda. J Clean Prod 15:203-217. https://doi.org/10.1016/j.jclepro.2005.11.057

131. Zeyringer M, Pachauri S, Schmid E, Schmidt J, Worrell E, Morawetz UB (2015) Analyzing grid extension and stand-alone photovoltaic systems for the costeffective electrification of Kenya. Energy Sustain Dev 25:75-86. https://doi. org/10.1016/j.esd.2015.01.003 
132. Petri Y, Caldeira K (2015) Impacts of global warming on residential heating and cooling degree-days in the United States. Sci Rep 5:12427. https://doi. org/10.1038/srep12427

133. Pampuri L, Cereghetti N, Strepparava D, Caputo P (2016) Analysis of the electricity consumptions: a first step to develop a district cooling system. Sustain Cities Soc 23:23-36. https://doi.org/10.1016/j.scs.2016.02.015

134. Chiesa G, Grosso M (2015) Geo-climatic applicability of natural ventilative cooling in the Mediterranean area. Energy Build 107:376-391. https://doi. org/10.1016/j.enbuild.2015.08.043

135. Sakaguchi T, Tabata T (2015) 100\% electric power potential of PV, wind power, and biomass energy in Awaji island Japan. Renew Sustain Energy Rev 51:1156-1165. https://doi.org/10.1016/j.rser.2015.06.056

136. Dall'O' G, Galante A, Torri M (2012) A methodology for the energy performance classification of residential building stock on an urban scale. Energy Build 48:211-219. https://doi.org/10.1016/j.enbuild.2012.01.034

137. Delmastro C, Mutani G, Schranz L (2015) The evaluation of buildings energy consumption and the optimization of district heating networks: a GIS-based model. Int J Energy Environ Eng 3:1-9. https://doi.org/10.1007/s40095-0150161-5

138. Baker KJ, Rylatt RM (2008) Improving the prediction of UK domestic energydemand using annual consumption-data. Appl Energy 85:475-482. https:// doi.org/10.1016/j.apenergy.2007.09.004

139. Bayerisches Staatsministerium für Umwelt und Gesundheit, Bayerisches Staatsministerium für Wirtschaft, Infrastruktur, Verkehr und Technologie, Oberste Baubehörde im Bayerischen Staatsministerium des Innern. Leitfaden Energienutzungsplan 2011. https://www.bestellen.bayern.de/application/ applstarter?APPL=eshop\&DIR=eshop\&ACTIONxSETVAL(artdtl. htm,APGxNODENR:1325,AARTxNR:stmug_klima 00003,AARTxNODENR: 17783,USERxBODYURL:artdtl.htm,KATALOG:StMUG,AKATxNAME:StMUG,ALLE:. Accessed 18 Apr 2012

140. Stöglehner G, Narodoslawsky M, Steinmüller H, Steininger K, Weiss M, Mitter $\mathrm{H}$ et al (2011) PlanVision - Visionen für eine energieoptimierte Raumplanung. Projektendbericht. Gefördert aus Mitteln des Klima- und Energiefonds, vol. 1. Wien, pp. 1-216

141. Gadsden S, Rylatt M, Lomas K, Robinson D (2003) Predicting the urban solar fraction: a methodology for energy advisers and planners based on GIS. Energy Build 35:37-48. https://doi.org/10.1016/S0378-7788(02)00078-6

142. Rylatt RM, Gadsden SJ, Lomas KJ (2003) Methods of predicting urban domestic energy demand with reduced datasets: a review and a new GISbased approach. Build Serv Eng Res Technol 24:93-102. https://doi.org/10. 1191/0143624403bt061oa

143. Yu D, Tan H, Ruan Y (2012) An improved two-step floating catchment area method for supporting district building energy planning: a case study of Yongding County city, China. Appl Energy 95:156-163. https://doi.org/10. 1016/j.apenergy.2012.02.036

144. Vettorato D, Geneletti D, Zambelli P (2011) Spatial comparison of renewable energy supply and energy demand for low-carbon settlements. Cities 28 : 557-566. https://doi.org/10.1016/j.cities.2011.07.004

145. Ascione F, De Masi RF, de Rossi F, Fistola R, Sasso M, Vanoli GP (2013) Analysis and diagnosis of the energy performance of buildings and districts: methodology, validation and development of Urban Energy Maps. Cities 35: 270-283. https://doi.org/10.1016/j.cities.2013.04.012

146. Fichera A, Inturri G, La Greca P, Palermo V (2016) A model for mapping the energy consumption of buildings, transport and outdoor lighting of neighbourhoods. Cities 55:49-60. https://doi.org/10.1016/j.cities.2016.03.011

147. Diefenbach N, Cischinsky H, Rodenfels M, Clausnitzer KD (2010)

Datenerhebung zur energetischen Qualität und zu den

Modernisierungstrends im deutschen Wohngebäudebestand. IWU, Darmstadt 9, pp. 1-180

148. Mitter H. Versorgung mit Biomasse-Nahwärme als Planungsinhalt des Örtlichen Entwicklungskonzeptes am Beispiel St. Georgen am Walde/OÖ 2005. Universität für Bodenkultur Wien, Vienna

149. Anderson BR, Chapman PF, Cutland NG, Dickson CM, Doran SM, lles PJ et al (1997) BREDEM 8 - model description - the construction information service. Garston, Watford, UK

150. Erwig M, Schneider M, Güting RH (1997) Temporal and spatio-temporal data models and their expressive power. Fernuniv., Fachbereich Informatik. Fernuniversität Hagen, Hagen

151. Erwig M, Gu RH, Schneider M, Vazirgiannis M et al (1999) Spatio-temporal data types: an approach to modeling and querying moving objects in databases. Geolnformatica 3:269-296
152. Langran G (1993) Issues of implementing a spatiotemporal system. Int J Geogr Inf Syst 7:305-314. https://doi.org/10.1080/02693799308901963

153. Peuquet DJ, Duan N (1995) An event-based spatiotemporal data model (ESTDM) for temporal analysis of geographical data. Int J Geogr Inf Syst 9:724. https://doi.org/10.1080/02693799508902022

154. Peuquet DJ (1999) Time in GIS and geographical databases. Geogr Inf Syst 1:91-103

155. Wachowicz JM, Wachowiez M (1999) Object-oriented design for temporal GIS. Taylor \& Francis, Inc., Bristol, PA, USA

156. Pebesma E (2012) spacetime: Spatio-temporal data in r. J Stat Softw 51:1-30

157. Gebbert S, Pebesma E (2014) TGRASS: a temporal GIS for field based environmental modeling. Environ Model Softw 53:1-12. https://doi.org/10. 1016/j.envsoft.2013.11.001

158. Biberacher M (2008) GIS-based modeling approach for energy systems. Int J Energy Sect Manag 2:368-384. https://doi.org/10.1108/17506220810892937

159. Schmidt J, Cancella R, Pereira AO Jr (2016) An optimal mix of solar PV, wind and hydro power for a low-carbon electricity supply in Brazil. Renew Energy 85:137-147. https://doi.org/10.1016/j.renene.2015.06.010

160. Gass V, Schmidt J, Strauss F, Schmid E (2013) Assessing the economic wind power potential in Austria. Energy Policy 53:323-330. https://doi.org/10. 1016/j.enpol.2012.10.079

161. Zeyringer M, Simoes S, Mayr D, Schmid E, Schmidt J, Lind J et al (2013) Solar buildings in Austria: methodology to assess the potential for optimal PV deployment. 10th Int. Conf. Eur. Energy Mark. EEM. https://doi.org/10. 1109/EEM.2013.6607405

162. Ramirez Camargo L, Nitsch F, Gruber K, Dorner W (2018) Electricity selfsufficiency of single-family houses in Germany and the Czech Republic. Appl Energy 228:902-915. https://doi.org/10.1016/j.apenergy.2018.06.118

163. Hans-Ertel-Zentrum für Wetterforschung. COSMO Regional Reanalysis COSMO-REA6. 2017. http://reanalysis.meteo.uni-bonn.de/?COSMO-REA6. Accessed 24 Jan 2018

164. Niemi R, Mikkola J, Lund PD (2012) Urban energy systems with smart multicarrier energy networks and renewable energy generation. Renew Energy 48:524-536. https://doi.org/10.1016/j.renene.2012.05.017

165. Lund $P$ (2012) Large-scale urban renewable electricity schemes - integration and interfacing aspects. Energy Convers Manag 63:162-172. https://doi.org/10.1016/j. enconman.2012.01.037

166. Mikkola J, Lund PD (2014) Models for generating place and time dependent urban energy demand profiles. Appl Energy 130:256-264. https://doi.org/10. 1016/j.apenergy.2014.05.039

167. Lund PD, Mikkola J, Ypyä J (2014) Smart energy system design for large clean power schemes in urban areas. J Clean Prod. https://doi.org/10.1016/j. jclepro.2014.06.005

168. Robinson D, Haldi F, Kämpf J, Leroux P, Perez D, Rasheed A, Wilke U (2009) CitySim: Comprehensive micro-simulation of resource flows for sustainable urban planning. In Proc. Building Simulation, pp. 1083-1090

169. Fonseca JA, Nguyen T-A, Schlueter A, Marechal F (2016) City Energy Analyst (CEA): integrated framework for analysis and optimization of building energy systems in neighborhoods and city districts. Energy Build 113:202226. https://doi.org/10.1016/j.enbuild.2015.11.055

170. Kucuksari S, Khaleghi AM, Hamidi M, Zhang Y, Szidarovszky F, Bayraksan G et al (2014) An integrated GIS, optimization and simulation framework for optimal PV size and location in campus area environments. Appl Energy 113:1601-1613. https://doi.org/10.1016/j.apenergy.2013.09.002

171. Choi Y, Rayl J, Tammineedi C, Brownson JRS (2011) PV Analyst: coupling ArcGIS with TRNSYS to assess distributed photovoltaic potential in urban areas. Sol Energy 85:2924-2939. https://doi.org/10.1016/j.solener.2011.08.034

172. Srećković N, Lukač N, Žalik B, Štumberger G (2016) Determining roof surfaces suitable for the installation of PV (photovoltaic) systems, based on LiDAR (Light Detection And Ranging) data, pyranometer measurements, and distribution network configuration. Energy 96:404-414. https://doi.org/ 10.1016/j.energy.2015.12.078

173. Mavromatidis G, Orehounig K, Carmeliet J (2015) Evaluation of photovoltaic integration potential in a village. Sol Energy 121:152-168. https://doi.org/10. 1016/.j.solener.2015.03.044

174. Grandjean A, Adnot J, Binet G (2012) A review and an analysis of the residential electric load curve models. Renew Sustain Energy Rev 16:65396565. https://doi.org/10.1016/j.rser.2012.08.013

175. Yeo I-A, Yoon S-H, Yee J-J (2013) Development of an Environment and energy Geographical Information System (E-GIS) construction model to support environmentally friendly urban planning. Appl Energy 104:723-739. https://doi.org/10.1016/j.apenergy.2012.11.053 
176. Girardin L, Marechal F, Dubuis M, Calame-Darbellay N, Favrat D (2010) EnerGis: a geographical information based system for the evaluation of integrated energy conversion systems in urban areas. Energy 35:830-840. https://doi.org/10.1016/j.energy.2009.08.018

177. European Committee for Standardization. Energieeffizienz von Gebäuden Berechnung des Energiebedarfs für Heizung und Kühlung (ISO 13790:2008); Deutsche Fassung EN ISO 13790:2008 2008.

178. Kokogiannakis G, Strachan P, Clarke J (2008) Comparison of the simplified methods of the ISO 13790 standard and detailed modelling programs in a regulatory context. J Build Perform Simul 1:209-219. https://doi.org/10.1080/ 19401490802509388

179. Ramirez Camargo L (2012) A GIS-based method for predicting hourly domestic energy need for space conditioning and water heating of districts and municipalities. Universität für Bodenkultur Wien, Vienna

180. Fonseca JA, Schlueter A (2015) Integrated model for characterization of spatiotemporal building energy consumption patterns in neighborhoods and city districts. Appl Energy 142:247-265. https://doi.org/10.1016/j. apenergy.2014.12.068

181. Loga T, Balaras C, Šijanec Zavrl M, Corrado V, Corgnati S, Despretz H et al (2012) Application of building typologies for modelling the energy balance of the residential building stock. Institut Wohnen und Umwelt GmbH, Darmstadt, Germany

182. Kämpf JH, Robinson D (2007) A simplified thermal model to support analysis of urban resource flows. Energy Build 39:445-453. https://doi.org/ 10.1016/j.enbuild.2006.09.002

183. Ramirez Camargo L, Zink R, Dorner W, Stoeglehner G (2015) Spatiotemporal modeling of roof-top photovoltaic panels for improved technical potential assessment and electricity peak load offsetting at the municipal scale. Comput Environ Urban Syst 52:58-69. https://doi.org/10.1016/j. compenvurbsys.2015.03.002

184. Ramirez Camargo L, Dorner W, Rauch P, Stoeglehner G. Energiezonenplanung Plus (EZP+): Open-source Tool für die Planung von Fernwärmenetzen anhand von hochaufgelösten räumlich-zeitlichen Daten. In: Strobl J, Zagel B, Griesebner G, Blaschke T, editors. J Für Angew Geoinformatik 2017;3:109-119. doi:https://doi.org/10.14627/537633012.

185. Ramirez Camargo L, Zink R, Dorner W (2015) Spatiotemporal modeling for assessing complementarity of renewable energy sources in distributed energy systems. ISPRS Ann Photogramm Remote Sens Spat Inf Sci II-4/W2: 147-154. https://doi.org/10.5194/isprsannals-II-4-W2-147-2015

186. Ramirez Camargo L, Dorner W (2016) Impact of small-scale storage systems on the photovoltaic penetration potential at the municipal scale. Energy Procedia 97:133-140. https://doi.org/10.1016/j.egypro.2016.10.037

187. Oliphant TE (2007) Python for scientific computing. Comput Sci Eng 9:1020. https://doi.org/10.1109/MCSE.2007.58

188. van der Walt S, Colbert SC, Varoquaux G (2011) The NumPy array: a structure for efficient numerical computation. Comput Sci Eng 13:22-30. https://doi.org/10.1109/MCSE.2011.37

189. Jones E, Oliphant T, Peterson P (2015) SciPy: open source scientific tools for Python, 2001. Httpwww Scipy Org 73:86

190. McKinney W, others (2010) Data structures for statistical computing in python. Proc. 9th Python Sci. Conf 445:51-56

191. GDAL Development Team (2016) GDAL-geospatial data abstraction library. Open Source Geospatial Foundation, Delaware

192. Neteler M, Mitasova H (2008) Open source GIS: a grass GIS approach. Springer, New York

193. QGIS Project. QGIS user guide release 2016. Open Source Geospatial Foundation, Delaware

194. Lang T, Gloerfeld E, Girod B (2015) Don't just follow the sun - a global assessment of economic performance for residential building photovoltaics. Renew Sustain Energy Rev 42:932-951. https://doi.org/10. 1016/j.rser.2014.10.077

195. Zink R, Ramirez Camargo L, Reidelstürz P, Dorner W (2015) Photogrammetric point clouds for gis-based high-resolution estimation of solar radiation for roof-top solar systems. Surf. Models Geosci., Springer International Publishing, Cham

196. Bayerischen Staatsministerium des Innern, Bayerischen Staatsministerium der Finanzen, Bayerischen Staatsministerium für Wirtschaft, Infrastruktur, Verkehr und Technologie, Bayerischen Staatsministerium für Umwelt und Gesundheit, Bayerischen Staatsministerium für Ernährung, Landwirtschaft und Forsten (2011) Hinweise zur Planung und Genehmigung von Windkraftanlagen. Bayerischen Staatsministerium des Innern, Bayerischen
Staatsministerium der Finanzen, Bayerischen Staatsministerium für Wirtschaft, Infrastruktur, Verkehr und Technologie, Bayerischen Staatsministerium für Umwelt und Gesundheit, Bayerischen Staatsministerium für Ernährung, Landwirtschaft und Forsten, Munich

197. Ramirez Camargo L, Pagany R, Marquardt A (2014) Zeitlich und räumlich hochaufgelöste Modellierung der potentiellen solaren Einstrahlung - ein Methodenvergleich. In: Strobl J, Blaschke T, Griesebner G, Zagel B (eds) Angew. Geoinformatik 2014 Beitr. Zum 26 AGIT-Symp. Salzbg. Wichmann, Berlin, pp 143-152

198. Wald L, Albuisson M, Best C, Delamare C, Dumortier D, Gaboardi E et al (2002) SoDa: a project for the integration and exploitation of networked solar radiation databases. Environ. Commun. Inf. Soc., International Society for Environmental Protection, Vienna, Austria, pp 713-720

199. Ramirez Camargo L, Dorner W (2016) Comparison of satellite imagery based data, reanalysis data and statistical methods for mapping global solar radiation in the Lerma Valley (Salta, Argentina). Renew Energy 99:57-68. https://doi.org/10.1016/j.renene.2016.06.042

200. Esslinger P, Witzmann R (2012) Entwicklung und Verifikation eines Stochastischen Verbraucherlastmodells für Haushalte. Technische Universität Graz, Graz

201. Richardson I, Thomson M, Infield D (2008) A high-resolution domestic building occupancy model for energy demand simulations. Energy Build 40: 1560-1566. https://doi.org/10.1016/j.enbuild.2008.02.006

202. Widen J (2011) Correlations between large-scale solar and wind power in a future scenario for Sweden. IEEE Trans Sustain Energy 2:177-184. https://doi. org/10.1109/TSTE.2010.2101620

203. Hoicka CE, Rowlands IH (2011) Solar and wind resource complementarity: advancing options for renewable electricity integration in Ontario, Canada. Renew Energy 36:97-107. https://doi.org/10.1016/j.renene.2010.06.004

204. Biberacher M, Gadocha S, Zocher D (2008) GIS based model to optimize possible self sustaining regions in the context of a renewable energy supply. Proc. Int. Congr. Environ. Model. Softw. Univ. Politècnica Catalunya Barc. International International Environmental Modelling and Software Society, Manno

205. Baumann P, Merticariu V, Dumitru A, Misev D (2016) Standards-based services for big spatio-temporal data. ISPRS - Int Arch Photogramm Remote Sens Spat Inf Sci XLI-B4:691-699. https://doi.org/10.5194/ isprsarchives-XLI-B4-691-2016

206. Stoeglehner G, Niemetz N, Kettl K-H (2011) Spatial dimensions of sustainable energy systems: new visions for integrated spatial and energy planning. Energy Sustain Soc 1:1-9. https://doi.org/10.1186/2192-0567-1-2

207. Peer V, Stoeglehner G (2013) Universities as change agents for sustainability - framing the role of knowledge transfer and generation in regional development processes. J Clean Prod 44:85-95. https://doi.org/10.1016/j. jclepro.2012.12.003

208. Neugebauer G, Kretschmer F, Kollmann R, Narodoslawsky M, Ertl T, Stoeglehner $G$ (2015) Mapping thermal energy resource potentials from wastewater treatment plants. Sustainability 7:12988-13010. https://doi.org/ 10.3390/su71012988

\section{Ready to submit your research? Choose BMC and benefit from:}

- fast, convenient online submission

- thorough peer review by experienced researchers in your field

- rapid publication on acceptance

- support for research data, including large and complex data types

- gold Open Access which fosters wider collaboration and increased citations

- maximum visibility for your research: over $100 \mathrm{M}$ website views per year

At $\mathrm{BMC}$, research is always in progress.

Learn more biomedcentral.com/submissions 